DOI: https://doi.org/10.24297/jam.v20i.9088

\title{
Metallic Ratios in Primitive Pythagorean Triples : Metallic Means embedded in Pythagorean Triangles and other Right Triangles
}

\author{
Dr. Chetansing Rajput \\ M.B.B.S. Nair Hospital (Mumbai University) India, \\ Asst. Commissioner (Govt. of Maharashtra) \\ Email: chetansingkrajput@gmail.com \\ Website: https://goldenratiorajput.com/
}

\author{
Lecture Link 1 : https://youtu.be/LFW1saNOp20 \\ Lecture Link 2 : https://youtu.be/vBfVDaFnA2k \\ Lecture Link 3 : https://youtu.be/raosniXwRhw \\ Lecture Link 4 : https://youtu.be/74uF4sBqYjs \\ Lecture Link 5 : https://youtu.be/Qh2B1tMl8Bk
}

\begin{abstract}
The Primitive Pythagorean Triples are found to be the purest expressions of various Metallic Ratios. Each Metallic Mean is epitomized by one particular Pythagorean Triangle. Also, the Right Angled Triangles are found to be more "Metallic" than the Pentagons, Octagons or any other $\left(n^{2}+4\right)$ gons. The Primitive Pythagorean Triples, not the regular polygons, are the prototypical forms of all Metallic Means.
\end{abstract}

Keywords: Metallic Mean, Pythagoras Theorem, Right Triangle, Metallic Ratio Triads, Pythagorean Triples, Golden Ratio, Pascal's Triangle, Pythagorean Triangles, Metallic Ratio

\section{A Primitive Pythagorean Triple for each Metallic Mean $\left(\delta_{n}\right)$ :}

Author's previous paper titled "Golden Ratio" cited by the Wikipedia page on "Metallic Mean" [1] \& [2], among other works mentioned in the References, have already highlighted the underlying proposition that the Metallic Means are more closely associated with; and more holistically represented by the "Right Angled Triangles", rather than Pentagon, Octagon or any other ' $n^{2}+4$ 'gon.

The mathematical correlations between different Metallic Ratios, their Geometric Substantiation, their close correspondence with Pythagorean Triples and $p \equiv 1(\bmod 4)$ Primes, the intriguing Triads of Metallic Means, their presence in Pascal's Triangle, all such intriguing aspects of Metallic Means have been recently introduced in the series of papers mentioned in the Reference [1] to [10], and in the Video Lecture Links mentioned above.

Now, let us see the cardinal aspects of these Metallic Ratios.......... 


\section{A Primitive Pythagorean Triple for each Metallic Mean $\left(\boldsymbol{\delta}_{\mathbf{n}}\right)$}
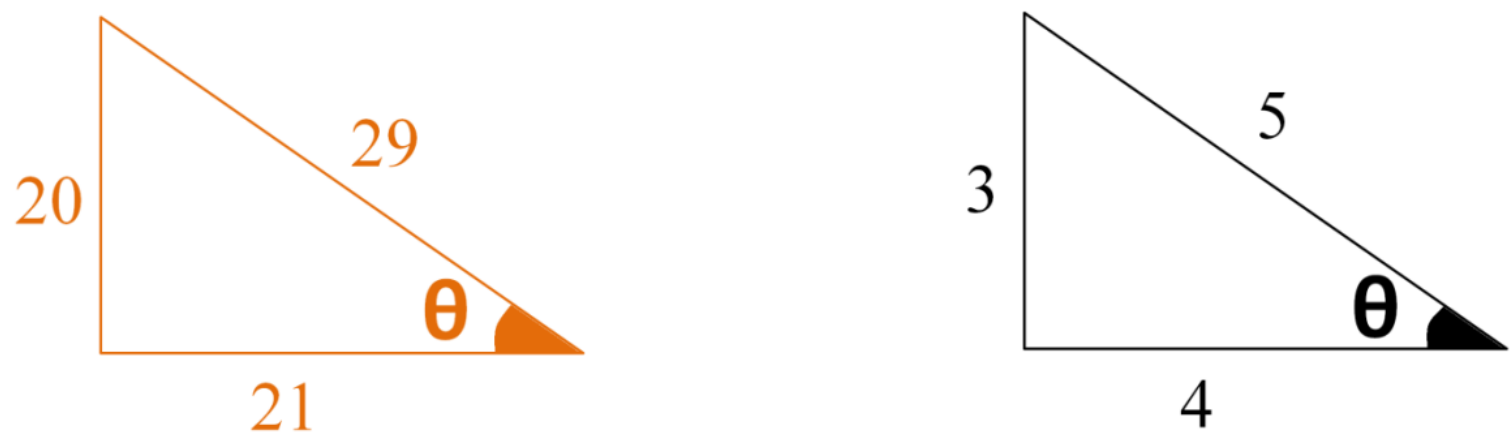

Fifth Metallic Mean :

$\delta_{5}=\cot \left(\frac{\theta}{4}\right)$

Sixth Metallic Mean :

$\delta_{6}=\cot \left(\frac{\theta}{4}\right)$
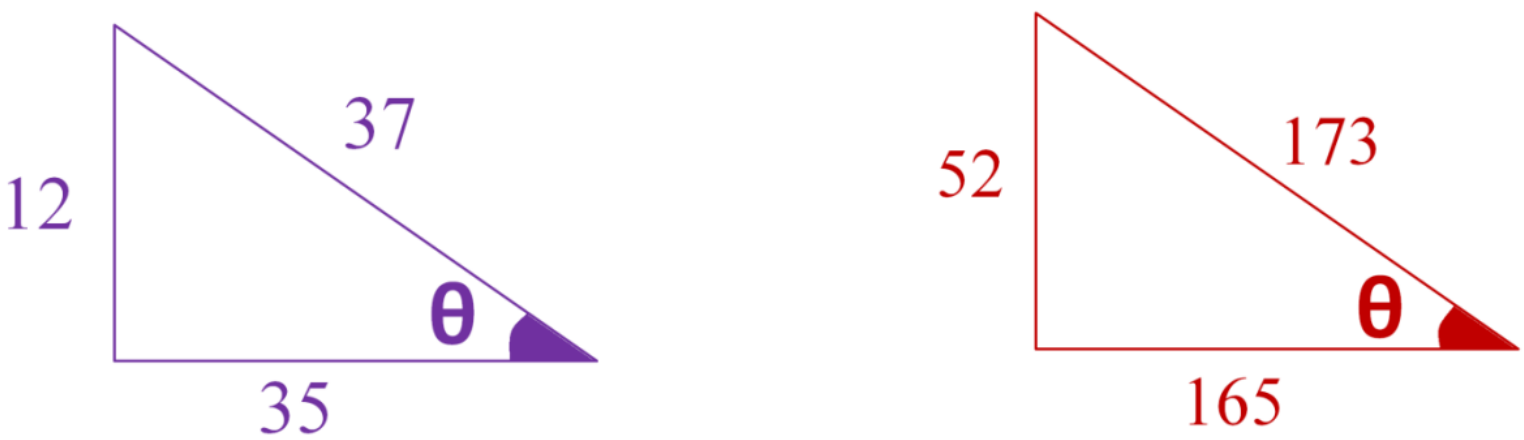

Twelfth Metallic Mean :

$$
\delta_{12}=\cot \left(\frac{\theta}{4}\right)
$$

Thirteenth Metallic Mean :

$$
\delta_{13}=\cot \left(\frac{\theta}{4}\right)
$$

Figure 1 : A Primitive Pythagorean Triple for each Metallic Mean 
A Pythagorean Triple $(\boldsymbol{a}, \boldsymbol{b}, \boldsymbol{c})$ epitomizes one particular Metallic Ratio, if its Hypotenuse minus Longer Cathetus $(\boldsymbol{c}-\boldsymbol{b})$ is equal to $\mathbf{1}, \mathbf{2}$ or $\mathbf{8}$.

If $(\mathbf{c}-\mathbf{b})=\mathbf{1}$ or $\mathbf{2}$ or $\mathbf{8}$ : such Pythagorean Triple $(\boldsymbol{a}, \boldsymbol{b}, \boldsymbol{c})$ manifests the $\mathrm{n}^{\text {th }}$ Metallic Ratio $\boldsymbol{\delta}_{\mathbf{n}}$ :

where $\mathbf{n}=2 \times \sqrt{\frac{(\mathbf{c}+\mathbf{b})}{(\boldsymbol{c}-\boldsymbol{b})}}$ and, the $\mathrm{n}^{\text {th }}$ Metallic Mean $\boldsymbol{\delta}_{\mathbf{n}}=\cot \frac{\boldsymbol{\theta}}{\mathbf{4}}$

where $\boldsymbol{\theta}$ is the Smaller Acute Angle of the associated Pythagorean Triangle (with specific variations for first four Metallic Means! )

Pythagorean Triple $(a, b, c)$ and $\mathbf{n}^{\text {th }}$ Metallic Mean $\left(\boldsymbol{\delta}_{\mathbf{n}}\right)$

$$
\begin{gathered}
\left(\frac{\mathbf{c}-\mathbf{b}}{\mathbf{8}}\right) \times 4 \mathrm{n}=\mathbf{a}=4 \times\left(\arctan \boldsymbol{\delta}_{\mathrm{n}}\right)-270^{\circ} \\
\mathbf{b}=\left(\delta_{\mathrm{n}}+\frac{1}{\delta_{\mathrm{n}}}\right)^{2} \times\left(\frac{\mathbf{c}-\mathbf{b}}{\mathbf{8}}\right)=\frac{\mathrm{L}_{\mathrm{n}}+\mathrm{L}_{\mathrm{n}-2}}{\mathrm{~F}_{\mathrm{n}-1}} \times\left(\frac{\mathrm{c}-\mathbf{b}}{8}\right) \times\left(\frac{\mathbf{c}-\mathbf{b}}{\mathbf{8}}\right) \\
\mathrm{\theta}=2 \sqrt{\frac{\mathrm{c}+\mathbf{b}}{\mathrm{c}-\mathbf{b}}}
\end{gathered}
$$

$$
\delta_{n}=\cot \left(\frac{\theta}{4}\right)=\tan \left(\frac{\Phi+270}{4}\right)
$$

Figure 2 : The Metallic Mean $\boldsymbol{\delta}_{\mathbf{n}}$ in the associated Primitive Pythagorean Triple 
Both the acute angles, both of the catheti as well as the Hypotenuse of such Pythagorean Triangle exhibit the corresponding Metallic Mean, as illustrated in above Figure.

Remarkably, the Hypotenuse $\mathbf{C}$ of such Triangle :

$$
\begin{aligned}
C & =\left(\delta_{n}+\frac{1}{\delta_{n}}\right)^{2} \times\left(\frac{c-b}{8}\right) \\
& =\left(n^{2}+4\right) \times\left(\frac{c-b}{8}\right) \\
& =\frac{L_{n}+L_{n-2}}{F_{n-1}} \times\left(\frac{c-b}{8}\right)
\end{aligned}
$$

where $F_{n}, F_{n+1} \ldots .$. is the Fibonacci-like Integer Sequence (Fibonacci Sequence for Golden Ratio, Pell Sequence for Silver Ratio, Bronze-Fibonacci Sequence for Bronze Ratio, etc.) and $L_{n}, L n+1 \ldots \ldots .$. is the corresponding Lucas Sequence associated with that particular Metallic Mean.

The following Table 1 shows associated Pythagorean Triples for first few Metallic Means:

Table 1: Primitive Pythagorean Triples associated with the Metallic Means $\boldsymbol{\delta}_{\mathbf{n}}$

\begin{tabular}{|c|c|}
\hline $\mathbf{n}$ & Associated Pythagorean Triple \\
\hline 1 & $3-4-5$ \\
\hline 2 & None \\
\hline 3 & $5-12-13$ \\
\hline 4 & $3-4-5$ \\
\hline 5 & $20-21-29$ \\
\hline 6 & $3-4-5$ \\
\hline 7 & $28-45-53$ \\
\hline 8 & $8-15-17$ \\
\hline 9 & $36-77-85$ \\
\hline 10 & $5-12-13$ \\
\hline 11 & $44-117-125$ \\
\hline 12 & $12-35-37$ \\
\hline 13 & $52-165-173$ \\
\hline 14 & $7-24-25$ \\
\hline 15 & $60-221-229$ \\
\hline 16 & $16-63-65$ \\
\hline 17 & $68-285-293$ \\
\hline 18 & $9-40-41$ \\
\hline 19 & $76-357-365$ \\
\hline 20 & $20-99-101$ \\
\hline & \\
\hline
\end{tabular}


Noticeably, certain patterns can be observed from above table.

Consider the radical $\left(n^{2}+4\right)$ in the fractional expression of the $n^{\text {th }}$ Metallic Mean : $\boldsymbol{\delta}_{n}=\frac{n+\sqrt{n^{2}+4}}{2}$

The $\mathrm{n}^{\text {th }}$ Metallic Mean $\boldsymbol{\delta}_{\mathbf{n}}$ is epitomized by such Primitive Pythagorean Triple whose Hypotenuse is Factor of this Radical $\left(n^{2}+4\right)$; with following sub-rules:

For $\mathbf{n}$ is Odd : $(c-b)=8$ and Hypotenuse of associated Pythagorean Triple : $c=\left(n^{2}+4\right)$, and the Smaller Cathetus of associated Pythagorean Triple $=4 n$

For $\mathbf{n}$ is Even and multiple of Four $(\mathbf{n}=\mathbf{4 x}):(c-b)=2$ and Hypotenuse of associated Pythagorean Triple : $\mathrm{c}=(\mathrm{nx}+1)=\frac{\left(\mathrm{n}^{2}+4\right)}{4} ;$ and the Smaller Cathetus of associated Pythagorean Triple $=\mathrm{n}$

For $\mathbf{n}$ is Even but not Multiple of Four : $(c-b)=1$ and Hypotenuse of associated Pythagorean Triple :

$\mathrm{C}=\frac{\left(\mathrm{n}^{2}+4\right)}{8}$ and the Smaller Cathetus of associated Pythagorean Triple $=\frac{\mathrm{n}}{2}$, and stuff like that.

Noteworthy here are the Special Cases of First Four Metallic Ratios : Noticeably, the same Pythagorean Triple 3-4-5 is associated with $\boldsymbol{\delta}_{\mathbf{4}}, \boldsymbol{\delta}_{\mathbf{6}}$ and the Golden Ratio $\boldsymbol{\delta}_{\mathbf{1}}$ or $\boldsymbol{\varphi}$

$\delta_{1}$ or $\varphi=\cot \left(\frac{180^{\circ}-\text { Larger Acute Angle of 3:4:5 Pythagorean Triangle }}{4}\right)$

$$
\begin{aligned}
& \delta_{4}=\cot \left(\frac{\text { Larger Acute Angle of 3:4:5 Pythagorean Triangle }}{4}\right) \\
& \boldsymbol{\delta}_{6}=\cot \left(\frac{\text { Smaller Acute Angle of 3:4:5 Pythagorean Triangle }}{4}\right)
\end{aligned}
$$

Similarly, same Pythagorean Triple $\mathbf{5 - 1 2 - 1 3}$ is associated with $\boldsymbol{\delta}_{\mathbf{3}}$ and $\boldsymbol{\delta}_{\mathbf{1 0}}$

$$
\begin{aligned}
& \delta_{3}=\cot \left(\frac{\text { Larger Acute Angle of 5:12:13 Pythagorean Triangle }}{4}\right) \\
& \delta_{10}=\cot \left(\frac{\text { Smaller Acute Angle of 5:12:13 Pythagorean Triangle }}{4}\right)
\end{aligned}
$$

From the Fifth Metallic Ratio onwards, any $\mathrm{n}^{\text {th }}$ Metallic Mean $\boldsymbol{\delta}_{\mathbf{n}}$ is given by the generalized formula:

$$
\delta_{n}=\cot \left(\frac{\text { Smaller Acute Angle of Associated Pythagorean Triangle }}{4}\right)
$$


And, $\boldsymbol{\delta}_{\mathbf{5}}$ onwards, each $\boldsymbol{\delta}_{\mathbf{n}}$ has its own distinctive associated Triple, no other Metallic Means have common associated Pythagorean Triples.

Moreover, the Silver Ratio $\boldsymbol{\delta}_{\mathbf{2}}$ has No associated Pythagorean Triple : as one of the Acute Angles of possible Pythagorean Triple associated with Silver Ratio would be $\left(4 \arctan \delta_{2}-270^{\circ}\right)$ that equals Zero Degrees, moreover $\left(\delta_{2}+\frac{1}{\delta_{2}}\right)^{2}$ equals 8 and there is no Pythagorean Triple having Hypotenuse 1, 2 or 8 . Another important reason for not having any Pythagorean Triple that may represent $\delta_{2}$ would become obvious in the subsequent part of this paper. Noteworthy here, this Silver Ratio forms "TRIADS" with $\boldsymbol{\delta}_{\mathbf{1}}, \boldsymbol{\delta}_{\mathbf{4}}$ and $\boldsymbol{\delta}_{\mathbf{6}}$ (the Metallic Means having common associated Pythagorean Triple 3-4-5); and also with $\boldsymbol{\delta}_{\mathbf{3}}$ and $\boldsymbol{\delta}_{10}$ (the Metallic Means having common associated Pythagorean Triple 5-12-13). The concept of these "TRIADS of Metallic Means" will be elaborated in the subsequent part of this paper.

\section{Right Triangles are more "Metallic" than any ' $n^{2}+4$ 'gon}

Golden Ratio in regular Pentagon and Silver Ratio in regular Octagon, but contrary to natural expectations, the Tridecagon could not substantiate the Bronze Ratio, or $\boldsymbol{\delta}_{\mathbf{5}}$ is not observed in 29-gon. While these $\left(\mathrm{n}^{2}+4\right)$ gons could yield no more Metallic Ratios, the Right Angled Triangles are the newly discovered "Metallic Mines" waiting to be exploited....!

Each Metallic Ratio can be constructed geometrically with a special Right Angled Triangle. Any $\mathrm{n}^{\text {th }}$ Metallic Mean can be represented by the Right Triangle having its catheti $\mathbf{1}$ and $\frac{\mathbf{n}}{\mathbf{2}}$. Hence, the right triangle with one of its catheti $=\mathbf{1}$ may substantiate any Metallic Mean, having its second cathetus $=\frac{\mathbf{n}}{\mathbf{2}}$, where $\mathrm{n}=1$ for Golden Ratio, $\mathrm{n}=2$ for Silver Ratio, $\mathrm{n}=3$ for Bronze Ratio, and so on. Such Right Triangle provides the precise value of $\mathrm{n}^{\text {th }}$ Metallic Mean by the generalised formula:

$$
\text { The } \mathrm{n}^{\text {th }} \text { Metallic Mean }\left(\boldsymbol{\delta}_{\mathrm{n}}\right)=\text { Hypotenuse }+ \text { Cathetus } \frac{\mathrm{n}}{2}
$$

This Generalised Geometric Construction of all Metallic Ratios: cited by the Wikipedia in its page on "Metallic Mean" [1]. This generalised geometric substantiation of all Metallic Means was published in author's previous paper titled Golden Ratio [2].

Note, for $\mathbf{n = 1}$ : the right Triangle that represents Golden Ratio has its Cathetus 1 longer than its Second Cathetus $\frac{\mathrm{n}}{2}$

And, in case of $\mathbf{n = 2}$ : the Triangle representing Silver Ratio is an Isosceles Right Triangle.

Also, the Right Triangles those represent the First and Fourth Metallic Means: $\boldsymbol{\delta}_{\mathbf{1}}$ ( that is Golden Ratio $\boldsymbol{\varphi}$ ) and $\boldsymbol{\delta}_{\mathbf{4}}$ (which equals $\boldsymbol{\varphi}^{\mathbf{3}}$ ), are similar triangles. Hence, the abovementioned Special Cases are observed from First to Fourth Metallic Means. From $5^{\text {th }}$ Metallic Mean onwards, the generalised rules are applicable. 


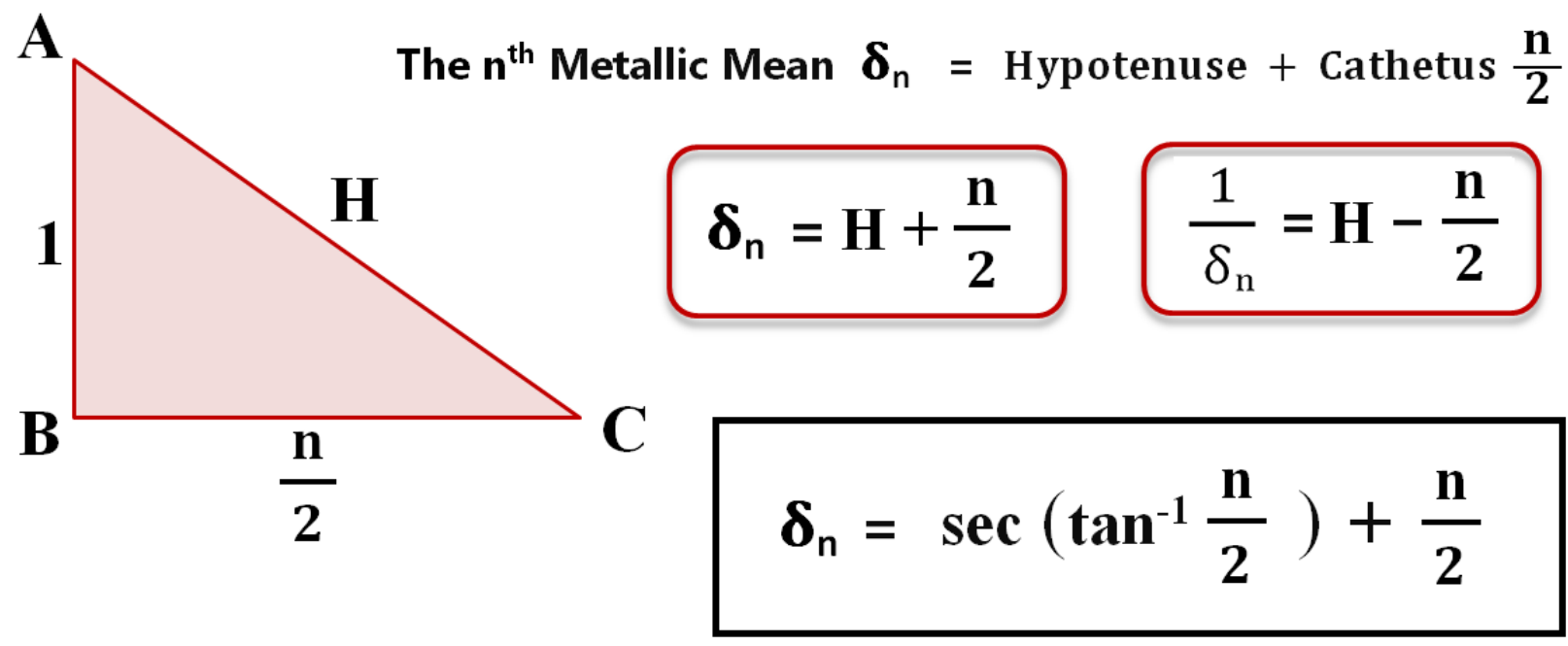

Figure 3: Generalised Geometric Construction of $\mathrm{n}^{\text {th }}$ Metallic Mean $\boldsymbol{\delta}_{\mathrm{n}}$ with $\mathbf{1}: \frac{\mathbf{n}}{\mathbf{2}}$ Right Triangle

Such Right Triangle not only provides for the accurate geometric construction and precise fractional expression of any $\mathrm{n}^{\text {th }}$ Metallic Mean, but its every geometric feature is the prototypical form of that Metallic Mean [2], and [4] to [7]. The characteristic geometry of such Right Triangle having its catheti $\mathbf{1}$ and $\frac{\mathbf{n}}{\mathbf{2}}$, is resplendent with the corresponding $\mathrm{n}^{\text {th }}$ Metallic Mean $\left(\boldsymbol{\delta}_{\mathbf{n}}\right)$ embedded in its every geometric aspect.

For example, the remarkable expression of Golden Ratio in every geometric feature of $1: 2: \sqrt{5}$ triangle, including all its angles and side lengths, its 'Incenter-Excenters Orthocentric system', its Gergonne and Nagel triangles, and also the Nobbs points and the Gergonne line, various triangle centers as well as the Incircle of $1: 2: \sqrt{5}$ triangle, make this triangle the quintessential form of the Golden Ratio $(\varphi)$ and also of the fourth Metallic Mean $\left(\varphi^{3}\right)$. [2]

Moreover, such Fractional Expression Triangle is also the Limiting Triangle for the Pythagorean Triples formed with the Hypotenuses those equal the alternate terms of the Integer Sequence associated with that Metallic Mean $\left(\boldsymbol{\delta}_{\mathbf{n}}\right)$. For example, the Pythagorean triples derived from Fibonacci series, approach the 1:2: $\sqrt{5}$ triangle's proportions, as the series advances. Likewise, the Pythagorean triples having alternate Pell Numbers as their Hypotenuses, approach the 1:1: $\sqrt{2}$ triangle's proportions, as the series advances, and so on.

\section{Metallic Ratios and various Right Triangles :}

Remarkably, all Metallic Ratios can be precisely expressed with various Right Angled Triangles. Three of the more intriguing such triangles are :

1) The abovementioned $\mathbf{1}: \frac{\mathbf{n}}{\mathbf{2}}$ Right Triangle

2) The $\mathbf{1}: \boldsymbol{\delta}_{\text {n }}$ Right Triangle

3) The Primitive Pythagorean Triples associated with each Metallic Mean $\boldsymbol{\delta}_{\mathrm{n}}$

These three Right Angled Triangles not only epitomize the Metallic Ratios, but they also exhibit the classical geometric correspondence with each other, as illustrated below in Figure 4. 


\section{Three Right Triangles}

associated with each Metallic Mean $\boldsymbol{\delta}_{\mathbf{n}}$

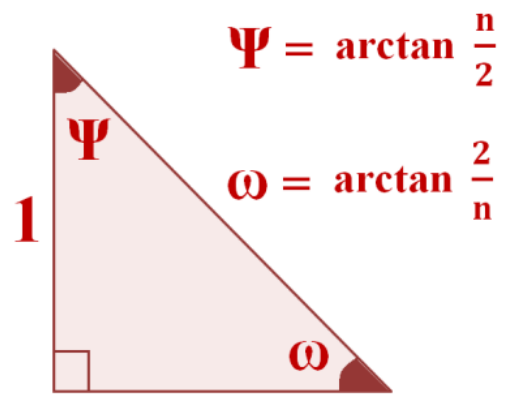

$\mathrm{n} / 2$

Metallic Ratio $\boldsymbol{\delta}_{\mathrm{n}}=$ Hypotenuse + Cathetus $\left(\frac{\mathrm{n}}{2}\right)$ $\alpha=\arctan \delta_{\mathrm{n}}$

$\beta=\arctan \frac{1}{\delta_{\mathrm{n}}}$

$\beta$

$$
\delta_{\mathrm{n}}
$$

Metallic Ratio $\boldsymbol{\delta}_{\mathrm{n}}=$

Ratio between Two Catheti

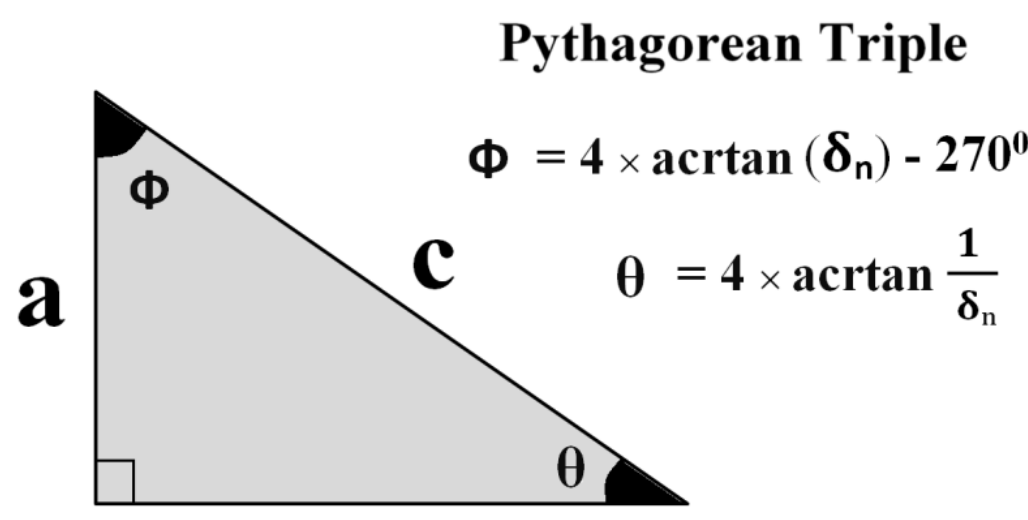

b

Metallic Ratio $\delta_{\mathrm{n}}=\cot \left(\frac{\theta}{4}\right)$
$\Psi+2 \beta=90^{0}$

$\omega+2 \alpha=180^{0}$

$2 \beta=\omega$

$\boldsymbol{\Psi}+\boldsymbol{\beta}=\boldsymbol{\alpha}$

$\theta=2 \omega=4 \beta$

$\frac{\theta}{2}+2 \alpha=180^{0}$

$2 \Psi-\Phi=90^{0}$

Figure 4: Three Right Angled Triangles personifying Metallic Means 
$\arctan \frac{\mathbf{n}}{2}$ is the Complimentary Angle of $2 \arctan \frac{1}{\delta_{n}}$ $\arctan \frac{2}{n}$ is the Supplementary Angle of $2 \arctan \delta_{n}$

$2 \arctan \frac{1}{\delta_{n}}=\arctan \frac{2}{n}$

$\arctan \frac{1}{\delta_{n}}+\arctan \frac{n}{2}=\arctan \delta_{n}$

Noticeably, the 1:2: $\sqrt{5}$ triangle, which is the $1: \frac{\mathbf{n}}{2}$ Right Triangle for Golden Ratio, exhibits the similar but inverse relationship with associated 3-4-5 Pythagorean Triple. The angle $36.87^{\circ}$ of 3-4-5 triangle is the complementary angle for twice the $26.565^{\circ}$ angle of $1: 2: \sqrt{5}$ triangle, while the angle $53.13^{0}$ of $3-4-5$ triangle is the supplementary angle for twice the $63.435^{\circ}$ angle of $1: 2: \sqrt{5}$ triangle. Further, two smaller acute angles of the two triangles, $26.565^{\circ} \& 36.87^{\circ}$, add up to angle $63.435^{\circ}$ of $1: 2: \sqrt{5}$ triangle, while the angle $53.13^{\circ}$ of Pythagorean triple is twice the $26.565^{\circ}$ angle of $1: 2: \sqrt{5}$ triangle. The classical geometric relationship between these two right triangles has been described in detail in the work mentioned in References [2] and [6].

Moreover,

Smaller Acute Angle of associated Pythagorean Triple $=2 \arctan \frac{2}{n}=4 \arctan \frac{1}{\delta_{n}}$

Hence remarkably, the Doubling of the Smaller Acute Angle of the $\mathbf{1}: \frac{\mathbf{n}}{\mathbf{2}}$ Right Triangle for any $\mathrm{n}^{\text {th }}$ Metallic Mean $\left(\boldsymbol{\delta}_{\mathbf{n}}\right)$ produces the associated Pythagorean Triple, while Halving that Smaller Acute Angle produces the 1: $\boldsymbol{\delta}_{\mathbf{n}}$ right triangle. (This is another reason why Silver Ratio $\delta_{2}$ has No associated Pythagorean Triple, as doubling the acute angle of 1-1- $\sqrt{\mathbf{2}}$ Isosceles Triangle would be $\mathbf{9 0}^{\mathbf{0}}$.)

\section{Right Angled Triangles and the "TRIADS" Of Metallic Means :}

If $\mathbf{K}, \mathbf{m}$ and $\mathbf{n}$ are three positive integers such that $\mathbf{n}$ is the smallest of the three integers and $\frac{\mathbf{m n}+\mathbf{4}}{\mathbf{m}-\mathbf{n}}=\mathbf{k}$ then, it is observed that

$\frac{\boldsymbol{\delta}_{\mathrm{m}} \times \boldsymbol{\delta}_{\mathrm{n}}+\mathbf{1}}{\boldsymbol{\delta}_{\mathrm{m}}-\boldsymbol{\delta}_{\mathrm{n}}}=\boldsymbol{\delta}_{\mathrm{k}}$ where $\boldsymbol{\delta}_{\mathrm{k}}, \boldsymbol{\delta}_{\mathrm{m}}$ and $\boldsymbol{\delta}_{\mathrm{n}}$ are the $\mathrm{k}^{\text {th }}, \mathrm{m}^{\text {th }}$ and $\mathrm{n}^{\text {th }}$ Metallic Means respectively.

This explicit formula, among several other formulae those give the precise mathematical relations between different Metallic Means, has been recently published in the work mentioned in Reference [3].

The abovementioned explicit formula gives the "Triads" of Metallic Means as $\left[\boldsymbol{\delta}_{\mathrm{n}}, \boldsymbol{\delta}_{\mathrm{m}}, \boldsymbol{\delta}_{\mathrm{k}}\right]$ 
If $\frac{\mathbf{m n}+\mathbf{4}}{\mathbf{m}-\mathbf{n}}=\mathbf{k}$ and $\frac{\mathbf{k n}+\mathbf{4}}{\mathbf{k}-\mathbf{n}}=\mathbf{m}$

then, $\frac{\boldsymbol{\delta}_{\mathrm{m}} \times \boldsymbol{\delta}_{\mathrm{n}}+\mathbf{1}}{\boldsymbol{\delta}_{\mathrm{m}}-\boldsymbol{\delta}_{\mathrm{n}}}=\boldsymbol{\delta}_{\mathrm{k}}$ and also $\frac{\boldsymbol{\delta}_{\mathrm{k}} \times \boldsymbol{\delta}_{\mathrm{n}}+\mathbf{1}}{\boldsymbol{\delta}_{\mathrm{k}}-\boldsymbol{\delta}_{\mathrm{n}}}=\boldsymbol{\delta}_{\mathrm{m}}$

Moreover,

$$
\frac{\mathbf{k m}-4}{\mathbf{k}+\mathbf{m}}=\mathbf{n} \quad \text { and } \quad \frac{\boldsymbol{\delta}_{\mathrm{k}} \times \boldsymbol{\delta}_{\mathrm{m}}-\mathbf{1}}{\boldsymbol{\delta}_{\mathrm{k}}+\boldsymbol{\delta}_{\mathrm{m}}}=\boldsymbol{\delta}_{\mathbf{n}}
$$

For example, if $n=6$, the three integers 6,11 and 14 satisfy the prerequisite $\frac{\mathbf{m n}+\mathbf{4}}{\mathbf{m}-\mathbf{n}}=\mathbf{k}$;

Hence, the three Metallic means $\boldsymbol{\delta}_{6}, \boldsymbol{\delta}_{11}$ and $\boldsymbol{\delta}_{14}$ form a Triad $\left[\boldsymbol{\delta}_{6}, \boldsymbol{\delta}_{11}, \boldsymbol{\delta}_{14}\right]$ such that :

$$
\frac{\boldsymbol{\delta}_{11} \times \boldsymbol{\delta}_{6}+\mathbf{1}}{\boldsymbol{\delta}_{11}-\boldsymbol{\delta}_{6}}=\boldsymbol{\delta}_{\mathbf{1 4}} \quad \text { and also } \quad \frac{\boldsymbol{\delta}_{14} \times \boldsymbol{\delta}_{6}+\mathbf{1}}{\boldsymbol{\delta}_{14}-\boldsymbol{\delta}_{6}}=\boldsymbol{\delta}_{11} \quad \text { Also, } \frac{\boldsymbol{\delta}_{14} \times \boldsymbol{\delta}_{11}-\mathbf{1}}{\boldsymbol{\delta}_{14}+\boldsymbol{\delta}_{11}}=\boldsymbol{\delta}_{\mathbf{6}}
$$

Several properties of these Triads are described in the works mentioned in References, like presence of these Triads of Metallic Means in Pascal's Triangle [8], geometric substantiation of these Triads [7], etc.

However, more interestingly, the Pythagorean Triples associated with three Metallic Means in a TRIAD unveil certain patterns those are peculiar to these TRIADS. Consider three Pythagorean Triples associated with three Metallic Means in a TRIAD $\left[\boldsymbol{\delta}_{\mathrm{n}}, \boldsymbol{\delta}_{\mathrm{m}}, \boldsymbol{\delta}_{\mathrm{k}}\right]$. Remarkably, the product of Hypotenuses of two Triples associated with $\boldsymbol{\delta}_{\mathrm{n}}$ and $\boldsymbol{\delta}_{\mathrm{m}}$ equals the Hypotenuse of the Triple for $\boldsymbol{\delta}_{\mathrm{k}}: \mathbf{C}_{\mathbf{n}} \times \mathbf{C}_{\mathbf{m}}=\mathbf{C}_{\mathbf{k}}$

For instance, consider the TRIAD $\left[\boldsymbol{\delta}_{6}, \boldsymbol{\delta}_{7}, \boldsymbol{\delta}_{46}\right]$ :

and the associated Triples are: $3-4-5,28-45-53,23-264-265$

Likewise,

$\operatorname{TRIAD}\left[\boldsymbol{\delta}_{14}, \boldsymbol{\delta}_{16}, \boldsymbol{\delta}_{114}\right]: 7-24-25,16-63-65,57-1624-1625$

$\operatorname{TRIAD}\left[\boldsymbol{\delta}_{6}, \boldsymbol{\delta}_{11}, \boldsymbol{\delta}_{14}\right]: 3-4-5,44-117-125,7-24-25$

$\operatorname{TRIAD}\left[\boldsymbol{\delta}_{12}, \boldsymbol{\delta}_{13}, \boldsymbol{\delta}_{160}\right]: 12-35-37,52-165-173,160-6399-6401$

Remarkably, these Triads of Metallic Means can be represented geometrically with various Right Triangles, as shown below. For instance, the Triad $\left[\boldsymbol{\delta}_{\mathbf{n}}, \boldsymbol{\delta}_{\mathbf{m}}, \boldsymbol{\delta}_{\mathbf{k}}\right.$ ] is illustrated geometrically, in form of with $\mathbf{1}: \frac{\mathbf{n}}{\mathbf{2}}$ Right Triangles, in following Figure 5. 


\section{1: $\frac{\mathrm{n}}{2}$ Right Triangles for the "TRIAD" of Metallic Means}

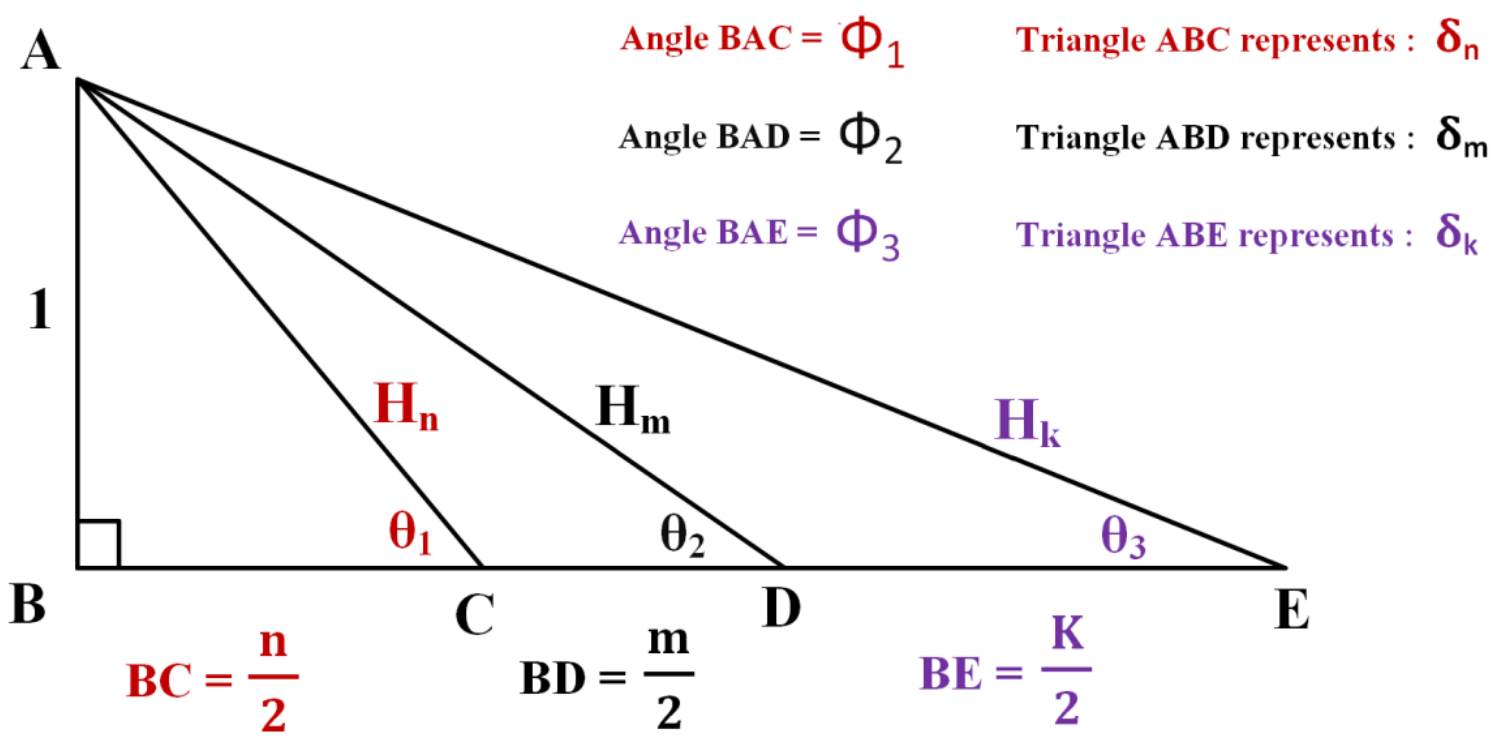

Figure 5: Three $1: \frac{\mathbf{n}}{\mathbf{2}}$ Right Triangles representing the "Triad of Metallic Means"

Remarkably, in above Figure 5: if the three Metallic Means $\boldsymbol{\delta}_{\mathbf{n}}, \boldsymbol{\delta}_{\mathbf{m}}$ and $\boldsymbol{\delta}_{\mathbf{k}}$ constitute a Triad as $\frac{\mathbf{m n}+\mathbf{4}}{\mathbf{m}-\mathbf{n}}=\mathbf{k}$, then it can be observed:

$\theta_{1}=\theta_{2}+\theta_{3} \quad\left(\right.$ and also $\left.\Phi_{1}+90^{0}=\Phi_{2}+\Phi_{3}\right)$

In other words,

$\arctan \frac{2}{\mathrm{n}}=\arctan \frac{2}{\mathrm{~m}}+\arctan \frac{2}{\mathrm{k}}$

Solving it gives the correlations: $\frac{\mathrm{mn}+4}{\mathrm{~m}-\mathrm{n}}=\mathbf{k}$ and $\frac{\mathrm{kn}+4}{\mathrm{k}-\mathrm{n}}=\mathbf{m}$

And also $\frac{\mathbf{k m}-4}{\mathrm{k}+\mathbf{m}}=\mathbf{n}$

And hence satisfy the prerequisite for $\frac{\boldsymbol{\delta}_{\mathrm{m}} \times \boldsymbol{\delta}_{\mathrm{n}}+\mathbf{1}}{\boldsymbol{\delta}_{\mathrm{m}}-\boldsymbol{\delta}_{\mathrm{n}}}=\boldsymbol{\delta}_{\mathrm{k}}$ and $\frac{\boldsymbol{\delta}_{\mathrm{k}} \times \boldsymbol{\delta}_{\mathrm{n}}+\mathbf{1}}{\boldsymbol{\delta}_{\mathrm{k}}-\boldsymbol{\delta}_{\mathrm{n}}}=\boldsymbol{\delta}_{\mathrm{m}}$

And also $\frac{\boldsymbol{\delta}_{\mathrm{k}} \times \boldsymbol{\delta}_{\mathrm{m}}-\mathbf{1}}{\boldsymbol{\delta}_{\mathrm{k}}+\boldsymbol{\delta}_{\mathrm{m}}}=\boldsymbol{\delta}_{\mathbf{n}}$ 
Moreover, the Hypotenuses of these Triad-Triangles: $\mathbf{H}_{\mathbf{n}}, \mathbf{H}_{\mathbf{m}}$ and $\mathbf{H}_{\mathbf{k}}$ in above Figure $\mathbf{5}$ exhibit following relations.

$$
\frac{\mathbf{H}_{\mathrm{k}}}{\mathbf{H}_{\mathrm{m}}}=\frac{\mathbf{2}}{\mathbf{m}-\mathbf{n}} \times \mathbf{H}_{\mathrm{n}}
$$

Simplifying this, we get $\frac{\mathrm{k}^{2}+4}{\mathrm{~m}^{2}+4}=\frac{\mathrm{n}^{2}+4}{(\mathrm{~m}-\mathrm{n})^{2}}$

And solving it gives $\mathbf{k}=\frac{\mathbf{m n}+\mathbf{4}}{\mathbf{m}-\mathbf{n}}$; which is the prerequisite for formation of a Triad $\left[\boldsymbol{\delta}_{\mathbf{n}}, \boldsymbol{\delta}_{\mathbf{m}}, \boldsymbol{\delta}_{\mathbf{k}}\right]$

Moreover, entire geometry of such Triad-Triangles is resplendent with the precise correlation among the three Metallic Means $\boldsymbol{\delta}_{\mathbf{n}}, \boldsymbol{\delta}_{\mathbf{m}}$ and $\boldsymbol{\delta}_{\mathbf{k}}$. Following intriguing relations are observed in above Figure 5. Consider the larger acute angles of the three triangles;

$$
\begin{aligned}
& \Phi_{2}+\Phi_{3}=2 \arctan \boldsymbol{\delta}_{\mathrm{n}} \\
& \Phi_{2}-\Phi_{1}=2 \arctan \frac{1}{\delta_{\mathrm{k}}} \\
& \Phi_{3}-\Phi_{1}=2 \arctan \frac{1}{\delta_{\mathrm{m}}}
\end{aligned}
$$

Similarly, $\arctan \frac{1}{\delta_{\mathrm{n}}}=\arctan \frac{1}{\delta_{\mathrm{m}}}+\arctan \frac{1}{\delta_{\mathrm{k}}}$

simplifying which we get : $\frac{\mathbf{k m}-\mathbf{4}}{\mathbf{k}+\mathbf{m}}=\mathbf{n} \quad$ and $\quad \frac{\boldsymbol{\delta}_{\mathrm{k}} \times \boldsymbol{\delta}_{\mathrm{m}}-\mathbf{1}}{\boldsymbol{\delta}_{\mathrm{k}}+\boldsymbol{\delta}_{\mathrm{m}}}=\boldsymbol{\delta}_{\mathbf{n}}$

And,

$\arctan \frac{1}{\delta_{\mathrm{n}}}+\arctan \frac{1}{\delta_{\mathrm{m}}}+\arctan \frac{1}{\delta_{\mathrm{k}}}=2 \arctan \frac{1}{\delta_{\mathrm{n}}}=\left(\theta_{1}\right)=\left[\theta_{2}+\theta_{3}\right]$

$=\arctan \frac{2}{\mathrm{n}}=\left[180^{\circ}-\left(\Phi_{2}+\Phi_{3}\right)\right]$

$=$ Half of the Smaller Acute Angle of the Pythagorean Triple for $\boldsymbol{\delta}_{\mathrm{n}}$ 
Similarly,

$\arctan \boldsymbol{\delta}_{\mathrm{n}}+90^{\circ}=\arctan \boldsymbol{\delta}_{\mathrm{m}}+\arctan \boldsymbol{\delta}_{\mathrm{k}}$

And,

$\arctan \boldsymbol{\delta}_{\mathrm{n}}+\arctan \boldsymbol{\delta}_{\mathrm{m}}+\arctan \boldsymbol{\delta}_{\mathrm{k}}=\Phi_{1}+180^{\circ}=\left(\Phi_{2}+\Phi_{3}\right)+90^{0}$

Moreover, these Triads of Metallic Means can also be represented with $\mathbf{1}: \boldsymbol{\delta}_{\mathrm{n}}$ Right Triangles, as shown below.

\section{1: $\delta_{\mathrm{n}}$ Right Triangles for the "TRIAD" of Metallic Means}

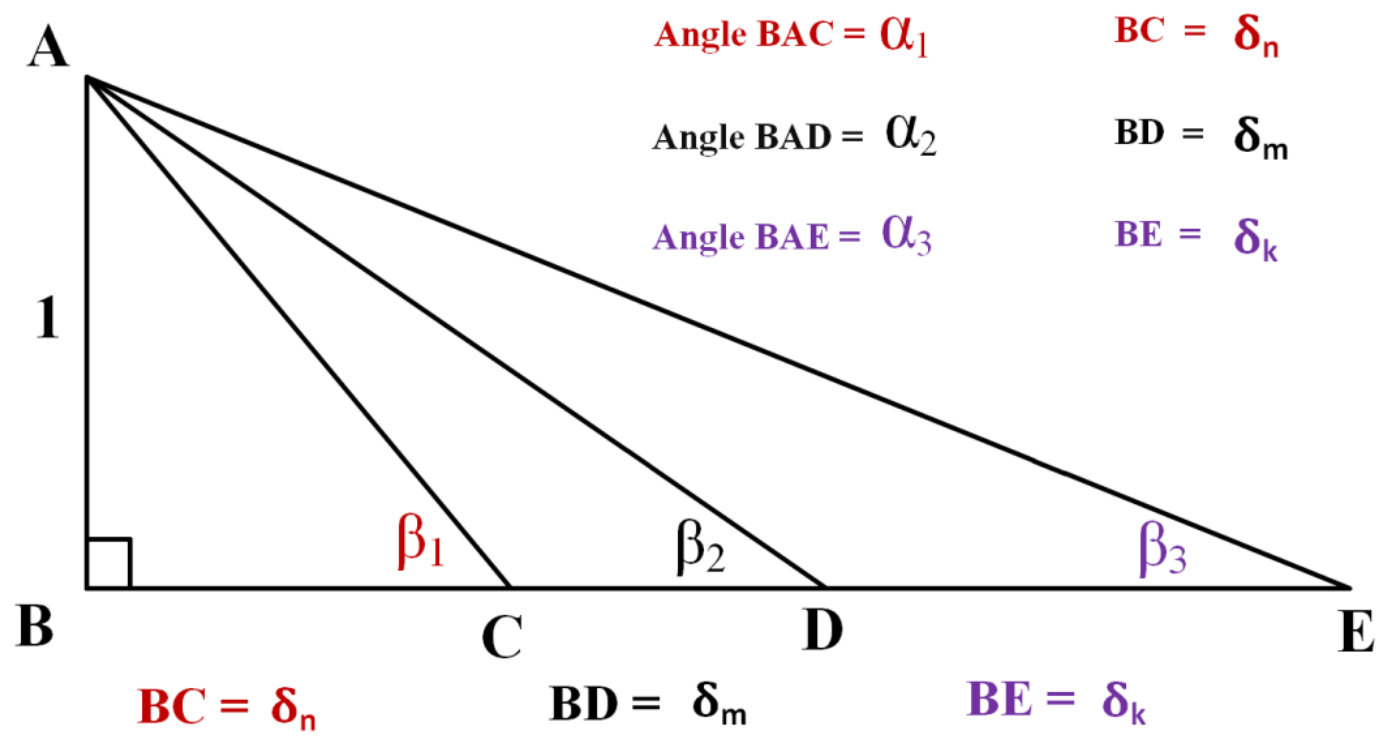

Figure 6 : Three 1: $\boldsymbol{\delta}_{\mathrm{n}}$ Right Triangles representing the "Triad of Metallic Means"

$\beta_{1}=\beta_{2}+\beta_{3}$ which is same as:

$\arctan \frac{1}{\delta_{\mathrm{n}}}=\arctan \frac{1}{\delta_{\mathrm{m}}}+\arctan \frac{1}{\delta_{\mathrm{k}}}$ 
Journal of Advances in Mathematics Vol 20 (2021) ISSN: 2347-1921

https://rajpub.com/index.php/jam

Similarly, $\quad \alpha_{1}+90^{0}=\alpha_{2}+\alpha_{3}$

Also,

$$
\begin{aligned}
& \alpha_{3}-\alpha_{1}=\beta_{2}=\arctan \frac{1}{\delta_{\mathrm{m}}} \\
& \alpha_{2}-\alpha_{1}=\beta_{3}=\arctan \frac{1}{\delta_{\mathrm{k}}}
\end{aligned}
$$

which are same as:

$\arctan \boldsymbol{\delta}_{\mathrm{k}}-\arctan \boldsymbol{\delta}_{\mathrm{n}}=\arctan \frac{1}{\delta_{\mathrm{m}}}$

$\arctan \boldsymbol{\delta}_{\mathrm{m}}-\arctan \boldsymbol{\delta}_{\mathrm{n}}=\arctan \frac{1}{\delta_{\mathrm{k}}}$

and these are nothing but the Trigonometric Forms of the equations:

$$
\frac{\boldsymbol{\delta}_{\mathrm{k}} \times \boldsymbol{\delta}_{\mathrm{n}}+1}{\boldsymbol{\delta}_{\mathrm{k}}-\boldsymbol{\delta}_{\mathrm{n}}}=\boldsymbol{\delta}_{\mathrm{m}} \text { and } \frac{\boldsymbol{\delta}_{\mathrm{m}} \times \boldsymbol{\delta}_{\mathrm{n}}+\mathbf{1}}{\boldsymbol{\delta}_{\mathrm{m}}-\boldsymbol{\delta}_{\mathrm{n}}}=\boldsymbol{\delta}_{\mathrm{k}}
$$

Moreover, consider above Figures 5 and $\mathbf{6}$ together. An intriguing correspondence is observed between the Triad-Triangles in those two figures.

$$
\begin{aligned}
\Phi_{2}+\Phi_{3} & =2 \alpha_{1} \\
\Phi_{2}-\Phi_{1} & =2 \beta_{3} \\
\Phi_{3}-\Phi_{1} & =2 \beta_{2} \\
\beta_{1}+\beta_{2}+\beta_{3} & =\left(\theta_{1}\right)=\left[\theta_{2}+\theta_{3}\right]=\arctan \frac{2}{n}=\left[180^{\circ}-\left(\Phi_{2}+\Phi_{3}\right)\right]
\end{aligned}
$$

Also,

$$
\alpha_{1}+\alpha_{2}+\alpha_{3}=\left(\Phi_{1}+180^{\circ}\right)=\left[\left(\Phi_{2}+\Phi_{3}\right)+90^{\circ}\right]
$$

325 


\section{Another Couple of Right Triangles for Metallic Means :}

It is worth mentioning here that a couple of other Right Triangles, having their Catheti equal to two terms of associated Fibonacci Sequences and corresponding Lucas Sequences, also epitomize the $\mathrm{n}^{\text {th }}$ Metallic Mean $\boldsymbol{\delta}_{\mathbf{n}}$ Consider a Right Triangle having its catheti $\mathbf{G}_{\mathbf{m}}$ and $\mathbf{G}_{\mathbf{m}+\mathbf{k}}$ which are the $\mathrm{m}^{\text {th }}$ and $(\mathrm{m}+\mathrm{k})^{\text {th }}$ terms of the Integer Sequence associated with the $\mathrm{n}^{\text {th }}$ Metallic Mean $\boldsymbol{\delta}_{\mathbf{n}}$, like Fibonacci Sequence for Golden Ratio, Pell Sequence for Silver Ratio, and so on. And, consider another Right Triangle having its catheti $\mathbf{L}_{\mathbf{m}}$ and $\mathbf{L}_{\mathbf{m}+\mathbf{k}}$ which are the $\mathrm{m}^{\text {th }}$ and $(\mathrm{m}+\mathrm{k})^{\text {th }}$ terms of the corresponding Lucas Sequence, provided $\mathbf{k}$ is an Odd positive integer. These two Right Triangles synergize with each other to impart the phenomenal expression of corresponding Metallic Mean $\boldsymbol{\delta}_{\mathbf{n}}$, as illustrated in Figures 7, 8 and $\mathbf{9}$ below.

Note in Figures $\mathbf{7}$ below : Catheti $\mathbf{1}$ and $\mathbf{2}$ are Second and Third Fibonacci Numbers, and Catheti $\mathbf{3}$ and $\mathbf{4}$ are corresponding Lucas Numbers. Hence, the 1:2: $\sqrt{5}$ and 3-4-5 Right Triangles synergize to produce Golden Ratio $\varphi$ :

$$
63.435^{0}+53.13^{0}=116.565^{0}=2 \arctan \varphi
$$
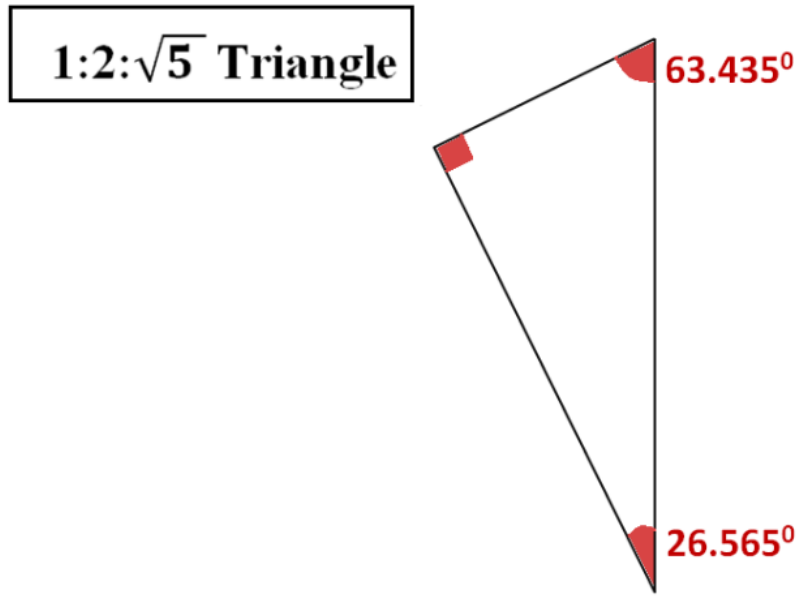

$$
26.565^{0}+36.87^{0}=63.435^{\circ}=2 \arctan \frac{1}{\varphi}
$$

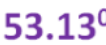

$36.87^{\circ}$

\section{3-4-5 Triangle}
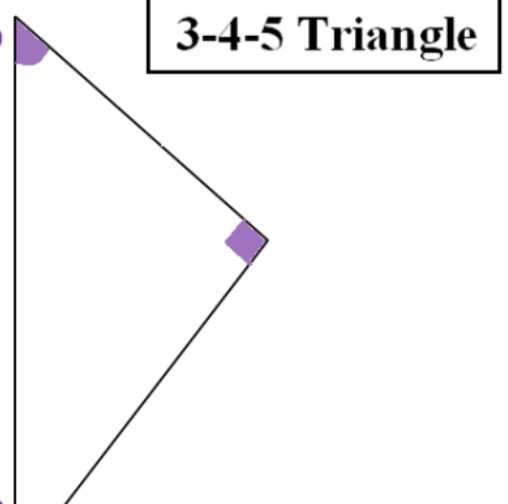

Figures 7 : Golden Ratio in the Amalgam of 1:2: $\sqrt{5}$ and 3-4-5 Right Triangles

And, this can be generalised as follows: Note $\mathbf{k}$ must be Odd Integer in following Figure 8 : 


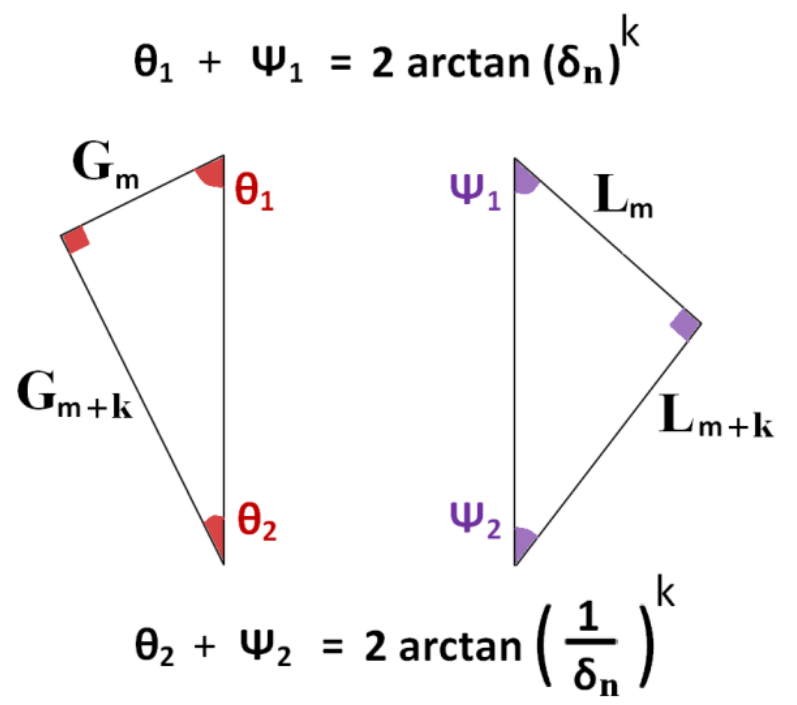

Deviation of all Four Acute Angles from arctangent of $\mathrm{K}^{\text {th }}$ power of Metallic Mean $=\tan ^{-1} \frac{1}{\left(\boldsymbol{\delta}_{\mathrm{n}}\right)^{2 \mathrm{~m}+\mathrm{k}}}$

Figures 8 : The $\mathrm{n}^{\text {th }}$ Metallic Mean $\boldsymbol{\delta}_{\mathbf{n}}$ in the Amalgam of Two Right Triangles

\section{Merger of Two Triangles along the Common Hypotenuse}
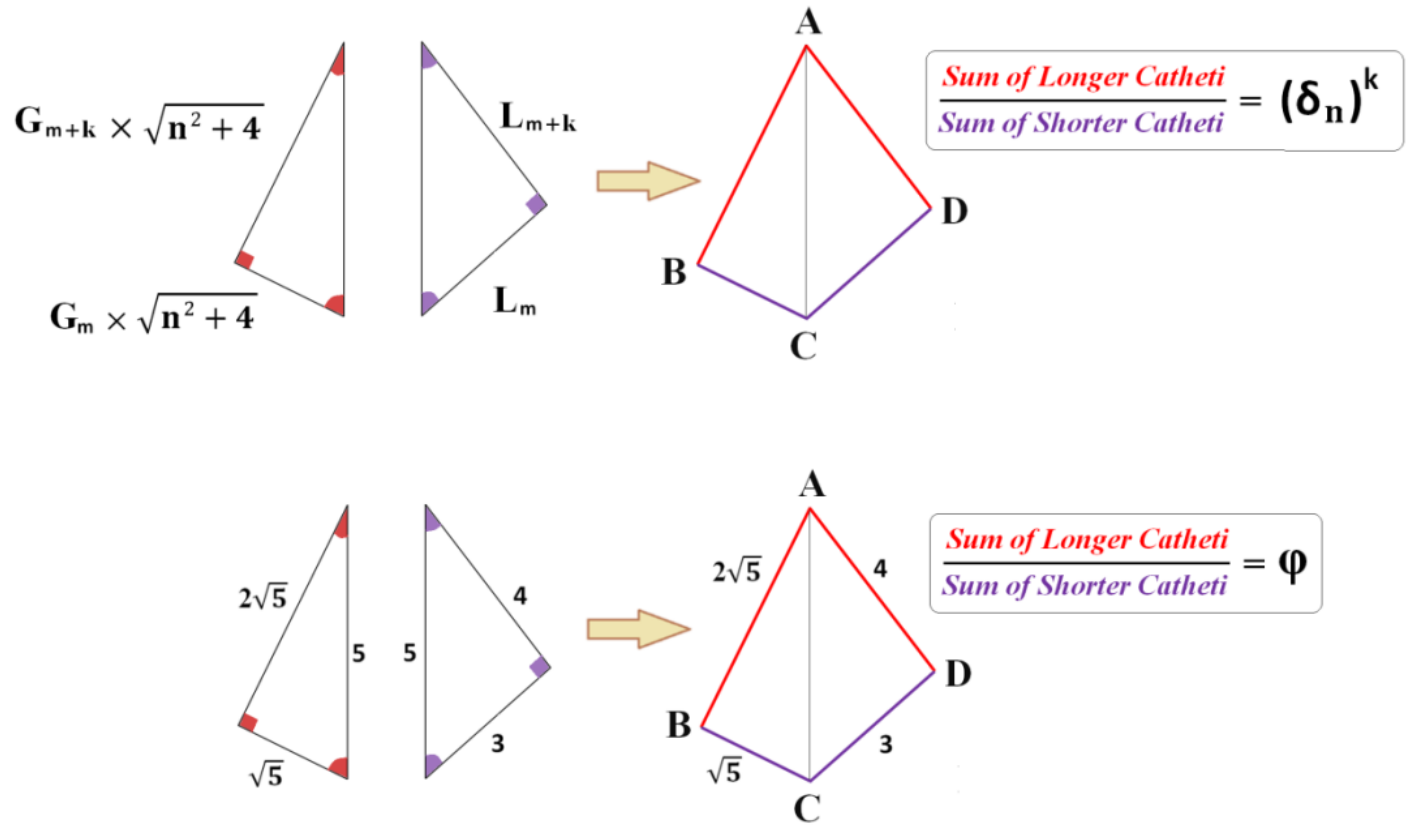

Figures 9 : The $\mathrm{n}^{\text {th }}$ Metallic Mean $\boldsymbol{\delta}_{\mathbf{n}}$ in the Amalgam of Two Right Triangles 
The geometric correspondence between such couple of Right Triangles is described in detail in the works mentioned in References [2] and [6].

\section{Metallic Means and Pythagorean Primes : The "Prime Families" of Metallic Means :}

From the close correspondence between Metallic Means and Pythagorean Triples described in this paper, it becomes obvious that various Metallic Means are also closely associated with different Pythagorean Primes.

Consider the radical $\left(\mathbf{n}^{2}+\mathbf{4}\right)$ in the Fractional expression of the $\mathrm{n}^{\text {th }}$ Metallic Mean $\left(\boldsymbol{\delta}_{\mathrm{n}}\right)$. By Fermat's Theorem on Sums of Two Squares, this radical is an integer multiple of a prime of the form $p \equiv 1$ (mod 4). The Greatest Prime Factor ( i.e. the Largest Prime Divisor) of this radical $\left(n^{2}+4\right)$ is a Pythagorean Prime, as shown below in Table 2.

\begin{tabular}{|c|c|c|}
\hline $\mathbf{n}$ & $\mathbf{n}^{2}+\mathbf{4}$ & $\begin{array}{c}\text { Greatest Prime Factor of } \\
\left(\mathbf{n}^{2}+\mathbf{4}\right):\end{array}$ \\
\hline 1 & 5 & 5 \\
\hline 2 & 8 & $2:$ Exception, Not $p \equiv 1$ (mod 4$)$ \\
\hline 3 & 13 & 5 \\
\hline 4 & 20 & 29 \\
\hline 5 & 29 & 5 \\
\hline 6 & 40 & 53 \\
\hline 7 & 53 & 17 \\
\hline 8 & 68 & 17 \\
\hline 9 & 85 & 13 \\
\hline 10 & 104 & 5 \\
\hline 11 & 125 & 173 \\
\hline 12 & 148 & \\
\hline 13 & 173 & \\
\hline
\end{tabular}




\begin{tabular}{|c|c|c|}
\hline 14 & 200 & 5 \\
\hline 15 & 229 & 229 \\
\hline 16 & 260 & 13 \\
\hline
\end{tabular}

Table 2: The Greatest Prime Factors of the radical $\left(n^{2}+4\right)$

It is noticeable from above table that multiple values of $n$ exhibit common Greatest Prime Factor of $\left(n^{2}+4\right)$.

For example, for $3^{\text {th }}, 10^{\text {th }}$ and $16^{\text {th }}$ Metallic Means, the common Greatest Prime Factor of the radical $\left(n^{2}+4\right)$ is 13.

Also, for $1^{\text {st }}, 4^{\text {th }}, 6^{\text {th }}, 11^{\text {th }}$ Metallic Means, the common Greatest Prime Factor of the radical $\left(n^{2}+4\right)$ is $\mathbf{5}$.

Hence, the different Metallic Means can be classified into various groups corresponding to the Greatest Prime Factor (GPF) of the radical $\left(\mathbf{n}^{2}+\mathbf{4}\right)$.

This GPF is necessarily a Pythagorean Prime $(4 x+1)$, as shown below in Table 3.

Table 3 : Prime Families of Metallic Means

\begin{tabular}{|c|c|}
\hline $\begin{array}{c}\text { Greatest Prime Factor } \\
(\text { GPF }) \\
\text { of }\left[n^{2}+4\right]\end{array}$ & $\begin{array}{r}n_{\mathbf{s}} \text { of the associated } \\
\text { Metallic Means }\left(\boldsymbol{\delta}_{\mathrm{n}}\right)\end{array}$ \\
\hline 5 & $1,4,6,11$ \\
\hline 13 & $3,10,16,29$ \\
\hline 17 & $8,9,26$ \\
\hline 29 & $5,24,34$ \\
\hline 37 & $12,25,49$ \\
\hline 41 & $18,23,59$ \\
\hline
\end{tabular}


Noticeably, as described in previous section: the Hypotenuse of associated Pythagorean Triple is a factor of $\left(n^{2}+4\right)$, and the associated Pythagorean Primes, as shown in Table 3 are the Greatest Prime Factors of $\left(n^{2}+4\right)$. Note: the $8^{\text {th }}$ and the $9^{\text {th }}$ Metallic Means both have Pythagorean Prime 17 as the GPF of their $\left(n^{2}+4\right)$, however they have different associated Primitive Pythagorean Triples, as shown in Table 1.

Moreover, consider the Triads of Metallic Means $\left[\boldsymbol{\delta}_{\mathbf{n}}, \boldsymbol{\delta}_{\mathbf{m}}, \boldsymbol{\delta}_{\mathbf{k}}\right]$. Noticeably Two of the Three Metallic Ratios forming such Triad, belong to same Prime Family i.e. Two of the Three Metallic Ratios have common Greatest Prime Factors of their respective $\left(n^{2}+4\right)$ radicals.

For example, consider the Triad $\left[\boldsymbol{\delta}_{\mathbf{4}}, \boldsymbol{\delta}_{\mathbf{5}}, \boldsymbol{\delta}_{\mathbf{2 4}}\right]: \boldsymbol{\delta}_{5}$, and $\boldsymbol{\delta}_{24}$ belong to the $\mathbf{2 9}$ prime family. Similarly, consider the Triad $\left[\boldsymbol{\delta}_{\mathbf{5}}, \boldsymbol{\delta}_{\mathbf{6}}, \boldsymbol{\delta}_{\mathbf{3 4}}\right]: \boldsymbol{\delta}_{5}$, and $\boldsymbol{\delta}_{34}$ belong to the $\mathbf{2 9}$ prime family.

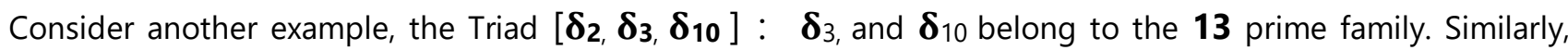
consider the Triad $\left[\boldsymbol{\delta}_{\mathbf{3}}, \boldsymbol{\delta}_{\mathbf{4}}, \boldsymbol{\delta}_{\mathbf{1 6}}\right]: \boldsymbol{\delta}_{3}$, and $\boldsymbol{\delta}_{16}$ belong to the $\mathbf{1 3}$ prime family.

Moreover, beside the Greatest Prime Factors indicated in above Table, multiple Pythagorean Primes constitute the factors of various $\left(n^{2}+4\right)$ radicals :

$(59)^{2}+4=41 \times 17 \times 5$

Likewise, $(49)^{2}+4=37 \times 13 \times 5$; and so on.

Remarkably, the Metallic Means belonging to same Prime Family exhibit very distinctive relations among themselves, as shown below.

The intriguing correlations among various Metallic Means, as illustrated by a couple of examples below, indicate that several more mathematical formulae can be generated to describe the precise relations between different Metallic Ratios. 
For instance, consider the Prime Family of Metallic Means associated with the Pythagorean Prime $\mathbf{1 3}: \boldsymbol{\delta}_{3}, \boldsymbol{\delta}_{10}$ and $\boldsymbol{\delta}_{16}$

Metallic Means associated with the Pythagorean Prime $13: \boldsymbol{\delta}_{3}, \boldsymbol{\delta}_{10}$ and $\boldsymbol{\delta}_{16}$

\section{Prime 13}

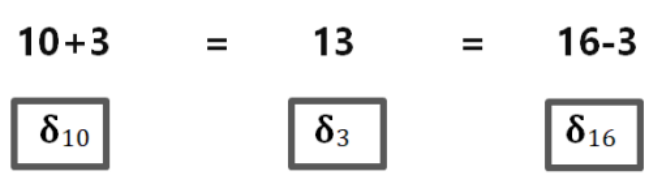

Hence, the Pythagorean Prime of this Family $13=\frac{3^{2}+4}{1}:$ Note the Digit 1 in Denominator.

Here, the $3^{\text {rd }}$ and $(3+1)^{\text {th }}$ Metallic Means give the precise value of $16^{\text {th }}$ Mean : $\frac{\boldsymbol{\delta}_{4} \times \boldsymbol{\delta}_{3}+\mathbf{1}}{\boldsymbol{\delta}_{4}-\boldsymbol{\delta}_{3}}=\boldsymbol{\delta}_{16}$

Similarly, the $3^{\text {rd }}$ and $(3-1)^{\text {th }}$ Metallic Means give the precise value of $10^{\text {th }}$ Mean : $\frac{\boldsymbol{\delta}_{3} \times \boldsymbol{\delta}_{2}+\mathbf{1}}{\boldsymbol{\delta}_{3}-\boldsymbol{\delta}_{2}}=\boldsymbol{\delta}_{10}$

Moreover, $\frac{\mathbf{1 3 - 1}}{\mathbf{2}}=6$ :this 6 forms a new Triad with members 10 and 16 of the family: $\left[\boldsymbol{\delta}_{6}, \boldsymbol{\delta}_{10}, \boldsymbol{\delta}_{16}\right]$ :

$$
\frac{\boldsymbol{\delta}_{16} \times \boldsymbol{\delta}_{6}+\mathbf{1}}{\boldsymbol{\delta}_{16}-\boldsymbol{\delta}_{6}}=\boldsymbol{\delta}_{10} \quad \text { and } \quad \frac{\boldsymbol{\delta}_{10} \times \boldsymbol{\delta}_{6}+\mathbf{1}}{\boldsymbol{\delta}_{10}-\boldsymbol{\delta}_{6}}=\boldsymbol{\delta}_{16}
$$

Further, beyond 3, 10 and 16, more members would be added in the family of Pythagorean Prime 17, next member in the family would be 29 which equals the sum of all smaller members in the family;

$3+10+16=29$ and, the Prime $13=29-16$

And,

$2 \times 16+3+1=36$ :this 36 forms a new Triad with members 16 and 29 of the family $\left[\boldsymbol{\delta}_{16}, \boldsymbol{\delta}_{29}, \boldsymbol{\delta}_{36}\right]$ :

$$
\frac{\boldsymbol{\delta}_{36} \times \boldsymbol{\delta}_{16}+\mathbf{1}}{\boldsymbol{\delta}_{36}-\boldsymbol{\delta}_{16}}=\boldsymbol{\delta}_{29} \quad \text { and } \quad \frac{\boldsymbol{\delta}_{29} \times \boldsymbol{\delta}_{16}+\mathbf{1}}{\boldsymbol{\delta}_{29}-\boldsymbol{\delta}_{16}}=\boldsymbol{\delta}_{36}
$$


Likewise, consider another example for illustration and comparison. the Metallic Means associated with the Pythagorean Prime $17: \boldsymbol{\delta}_{8}, \boldsymbol{\delta}_{9}$ and $\boldsymbol{\delta}_{26}$

Metallic Means associated with the Pythagorean Prime $17: \boldsymbol{\delta}_{8}, \boldsymbol{\delta}_{9}$ and $\boldsymbol{\delta}_{26}$

\section{Prime 17}

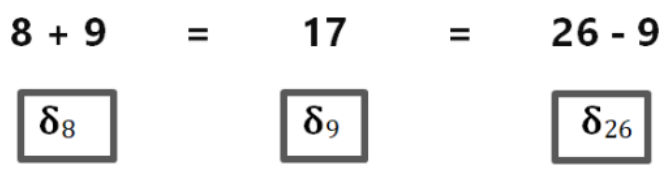

And, the Prime $17=\frac{9^{2}+4}{5}:$ Note the Digit 5 in Denominator.

Here, the $\boldsymbol{9}^{\text {th }}$ and $(\mathbf{9}+5)^{\text {th }}$ Metallic Means give the precise value of $\mathbf{2 6}^{\text {th }}$ Mean : $\frac{\boldsymbol{\delta}_{9} \times \boldsymbol{\delta}_{14}+\mathbf{1}}{\boldsymbol{\delta}_{14}-\boldsymbol{\delta}_{9}}=\boldsymbol{\delta}_{26}$

Similarly, the $\mathbf{9}^{\text {th }}$ and $(\mathbf{9}-\mathbf{5})^{\text {th }}$ Metallic Means give the precise value of $\mathbf{8}^{\text {th }}$ Mean : $\frac{\boldsymbol{\delta}_{9} \times \boldsymbol{\delta}_{4}+\mathbf{1}}{\boldsymbol{\delta}_{9}-\boldsymbol{\delta}_{4}}=\boldsymbol{\delta}_{8}$

Moreover, $\frac{\mathbf{1 7}-\mathbf{5}}{\mathbf{2}}=6$ : this 6 forms a new Triad with members 8 and 26 of the family: $\left[\boldsymbol{\delta}_{6}, \boldsymbol{\delta}_{8,}, \boldsymbol{\delta}_{26}\right]$

$$
\frac{\boldsymbol{\delta}_{26} \times \boldsymbol{\delta}_{6}+\mathbf{1}}{\boldsymbol{\delta}_{26}-\boldsymbol{\delta}_{6}}=\boldsymbol{\delta}_{8} \quad \text { and } \quad \frac{\boldsymbol{\delta}_{8} \times \boldsymbol{\delta}_{6}+\mathbf{1}}{\boldsymbol{\delta}_{8}-\boldsymbol{\delta}_{6}}=\boldsymbol{\delta}_{26}
$$

Further, beyond 8,9 and 26, more members would be added in the family of Pythagorean Prime 17, like next member in the family would be 43 which equals the sum of all smaller members in the family;

$8+9+26=43$ and, the Prime $17=43-26$

And,

$2 \times 26+9+5=66$ :this 66 forms a new Triad with members 26 and 43 of the family: $\left[\boldsymbol{\delta}_{26}, \boldsymbol{\delta}_{43}, \boldsymbol{\delta}_{66}\right]$

$$
\frac{\boldsymbol{\delta}_{66} \times \boldsymbol{\delta}_{26}+\mathbf{1}}{\boldsymbol{\delta}_{66}-\boldsymbol{\delta}_{26}}=\boldsymbol{\delta}_{43} \quad \text { and } \quad \frac{\boldsymbol{\delta}_{43} \times \boldsymbol{\delta}_{26}+\mathbf{1}}{\boldsymbol{\delta}_{43}-\boldsymbol{\delta}_{26}}=\boldsymbol{\delta}_{66}
$$

Such several distinctive correlations are observed among the Metallic Means belonging to the same Pythagorean Prime Families, and these correlations are bound to generate more such intriguing mathematical formulae, which may provide the precise relations between different Metallic Ratios. 


\section{3, 6 and 9 in the Realm of Metallic Means : Triangles, Triads, Triples, and now 3, 6, 9 !}

The proponents of Vortex Based Mathematics will continue to make irrational claims, and their opponents will continue to debunk them on grounds of the Base-10 Number System. Let the both camps do their jobs with missionary zeal!

Author's objective is just to appreciate the beauty of numbers and the special attributes of the digits 3,6 and 9, especially their unique patterns in the realm of Metallic Means.

Consider the Triads of Metallic Means $\left[\boldsymbol{\delta}_{\mathbf{n}}, \boldsymbol{\delta}_{\mathbf{m}}, \boldsymbol{\delta}_{\mathbf{k}}\right]$ with various integer values of $\mathrm{n}$, shown below in Table 4 .

Noticeably, in the following Table 4 :

If $\mathrm{n}$ is NOT multiple of 3 , the alternate values of $\mathbf{m}$ and $\mathbf{k}$ have their digital roots $3, \mathbf{6}$, or $\mathbf{9}$.

And, if $n$ is multiple of $3:$ None of the associated $m_{s}$ and $k_{s}$ have their digital roots 3,6 , or 9 .

Hence, only one of the $n, m$ and $k$ values in a Triad can have the Digital Root 3, 6 or 9.

Table 4: "Triads" of Metallic Means formed by the First Ten Metallic Means:

\begin{tabular}{|c|c|c|c|c|c|c|c|c|}
\hline $\mathrm{n}$ & 1 & 1 & 1 & 1 & 1 & 1 & 1 & 1 \\
\hline $\mathrm{m}$ & 2 & 6 & & & & & & \\
\hline $\mathrm{k}$ & 6 & 2 & & & & & & \\
\hline
\end{tabular}

\begin{tabular}{|l|l|l|l|l|l|l|l|l|}
\hline $\mathrm{n}$ & 2 & 2 & 2 & 2 & 2 & 2 & 2 & 2 \\
\hline $\mathrm{m}$ & 3 & 4 & 6 & 10 & & & & \\
\hline $\mathrm{k}$ & 10 & 6 & 4 & 3 & & & & \\
\hline
\end{tabular}

: Alternate $\mathrm{m}_{\mathrm{s}}$ and $\mathrm{k}_{\mathrm{s}}$ have their digital roots 3,6 , or 9 .

\begin{tabular}{|l|l|l|l|l|l|l|l|l|}
\hline $\mathrm{n}$ & 3 & 3 & 3 & 3 & 3 & 3 & 3 & 3 \\
\hline $\mathrm{m}$ & 4 & 16 & & & & & & \\
\hline $\mathrm{k}$ & 16 & 4 & & & & & & \\
\hline
\end{tabular}

For $n=3,6,9$ :

None of the associated $m_{s}$ and $k_{s}$ have their digital roots 3, 6, or 9 . 


\begin{tabular}{|l|l|l|l|l|l|l|l|l|}
\hline $\mathrm{n}$ & 4 & 4 & 4 & 4 & 4 & 4 & 4 & 4 \\
\hline $\mathrm{m}$ & 5 & 6 & 8 & 9 & 14 & 24 & & \\
\hline $\mathrm{k}$ & 24 & 14 & 9 & 8 & 6 & 5 & & \\
\hline
\end{tabular}

\begin{tabular}{|l|l|l|l|l|l|l|l|l|}
\hline $\mathrm{n}$ & 5 & 5 & 5 & 5 & 5 & 5 & 5 & 5 \\
\hline $\mathrm{m}$ & 6 & 34 & & & & & & \\
\hline $\mathrm{k}$ & 34 & 6 & & & & & & \\
\hline
\end{tabular}

\begin{tabular}{|l|l|l|l|l|l|l|l|l|}
\hline $\mathrm{n}$ & 6 & 6 & 6 & 6 & 6 & 6 & 6 & 6 \\
\hline $\mathrm{m}$ & 7 & 8 & 10 & 11 & 14 & 16 & 26 & 46 \\
\hline $\mathrm{k}$ & 46 & 26 & 16 & 14 & 11 & 10 & 8 & 7 \\
\hline
\end{tabular}

: None of the associated $m_{s}$ and $k_{s}$ have their digital roots 3 , 6 , or 9 .

\begin{tabular}{|l|l|l|l|l|l|l|l|l|}
\hline $\mathrm{n}$ & 7 & 7 & 7 & 7 & 7 & 7 & 7 & 7 \\
\hline $\mathrm{m}$ & 8 & 60 & & & & & & \\
\hline $\mathrm{k}$ & 60 & 8 & & & & & & \\
\hline
\end{tabular}

\begin{tabular}{|l|l|l|l|l|l|l|l|l|}
\hline $\mathrm{n}$ & 8 & 8 & 8 & 8 & 8 & 8 & 8 & 8 \\
\hline $\mathrm{m}$ & 9 & 10 & 12 & 25 & 42 & 76 & & \\
\hline $\mathrm{k}$ & 76 & 42 & 25 & 12 & 10 & 9 & & \\
\hline
\end{tabular}

\begin{tabular}{|l|l|l|l|l|l|l|l|l|}
\hline $\mathrm{n}$ & 9 & 9 & 9 & 9 & 9 & 9 & 9 & 9 \\
\hline $\mathrm{m}$ & 10 & 14 & 26 & 94 & & & & \\
\hline $\mathrm{k}$ & 94 & 26 & 14 & 10 & & & & \\
\hline
\end{tabular}

: None of the associated $m_{s}$ and $k_{s}$ have their digital roots $3,6,9$. 


\begin{tabular}{|l|l|l|l|l|l|l|l|l|}
\hline $\mathrm{n}$ & 10 & 10 & 10 & 10 & 10 & 10 & 10 & 10 \\
\hline $\mathrm{m}$ & 11 & 12 & 14 & 18 & 23 & 36 & 62 & 114 \\
\hline $\mathrm{k}$ & 114 & 62 & 36 & 23 & 18 & 14 & 12 & 11 \\
\hline
\end{tabular}

More remarkably, the number of Triads formed ( or the numbers of $\mathrm{m}_{\mathrm{s}}$ and $\mathrm{k}_{\mathrm{s}}$ ) increase noticeably for $\mathrm{n}=$ 6 and 9

For Even $n_{s}$ : the number of Triads exhibit noticeable rise at $n=6,16,26,36 \ldots \ldots$ and so on.

For Odd $n_{s}$ : the number of Triads exhibit noticeable rise at $n=9,19,29 \ldots \ldots$ and so on.

Moreover, it can be noticed from above Table : if $\mathbf{n}$ is multiple of $\mathbf{3}$, the Digital Root of $|\mathbf{k}-\mathbf{m}|$ is $\mathbf{3}, \mathbf{6}$ or $\mathbf{9}$.

And, if $\mathrm{n}$ is NOT multiple of 3, the Digital Root of NONE of the $|\mathrm{k}-\mathrm{m}|$ value is 3,6 or 9 .

\begin{tabular}{|l|l|l|l|l|l|l|l|l|}
\hline $\mathbf{n}$ & 3 & 3 & 3 & 3 & 3 & 3 & 3 & 3 \\
\hline $\mathrm{m}$ & 4 & 16 & & & & & & \\
\hline $\mathrm{k}$ & 16 & 4 & & & & & & \\
\hline$|\mathrm{k}-\mathrm{m}|$ & 12 & 12 & & & & & & \\
\hline
\end{tabular}

\begin{tabular}{|l|l|l|l|l|l|l|l|l|}
\hline $\mathrm{n}$ & 6 & 6 & 6 & 6 & 6 & 6 & 6 & 6 \\
\hline $\mathrm{m}$ & 7 & 8 & 10 & 11 & 14 & 16 & 26 & 46 \\
\hline $\mathrm{k}$ & 46 & 26 & 16 & 14 & 11 & 10 & 8 & 7 \\
\hline$|\mathrm{k}-\mathrm{m}|$ & 39 & 18 & 6 & 3 & 3 & 6 & 18 & 39 \\
\hline
\end{tabular}

\begin{tabular}{|l|l|l|l|l|l|l|l|l|}
\hline $\mathrm{n}$ & 9 & 9 & 9 & 9 & 9 & 9 & 9 & 9 \\
\hline $\mathrm{m}$ & 10 & 14 & 26 & 94 & & & & \\
\hline $\mathrm{k}$ & 94 & 26 & 14 & 10 & & & & \\
\hline$|\mathrm{k}-\mathrm{m}|$ & 84 & 12 & 12 & 84 & & & & \\
\hline
\end{tabular}


And, if $\mathrm{n}$ is NOT multiple of 3 , the Digital Roots of the $|\mathrm{k}-\mathrm{m}|$ value are $1,2,4,5,7,8 \ldots \ldots$.

Further, many more such intriguing patterns are embedded in the domain of Metallic Means.

For illustration, consider following couple of examples, based upon the formula $\frac{\boldsymbol{\delta}_{\mathrm{m}} \times \boldsymbol{\delta}_{\mathrm{n}}+\mathbf{1}}{\boldsymbol{\delta}_{\mathrm{m}}-\boldsymbol{\delta}_{\mathrm{n}}}=\boldsymbol{\delta}_{\mathrm{k}}$

Consider the Triads of Metallic Means formed with $n=6$, and the values of $(\mathbf{m}-\mathbf{n})$, as shown below.

\begin{tabular}{|c|l|l|l|l|l|l|l|l|}
\hline $\mathrm{n}$ & 6 & 6 & 6 & 6 & 6 & 6 & 6 & 6 \\
\hline $\mathrm{m}$ & 7 & 8 & 10 & 11 & 14 & 16 & 26 & 46 \\
\hline $\mathrm{m}-\mathrm{n}$ & 1 & 2 & 4 & 5 & 8 & 10 & 20 & 40 \\
\hline
\end{tabular}

Note the bottom row in above table which contains the values of $(\mathbf{m}-\mathbf{n})$.

The numbers in this $(m-n)$ row exhibit typical $1: 2: 4: 5: 8: 10 \times(1: 2: 4)$ pattern, and remarkably the numbers 3,6 and 9 are conspicuous by their absence from this row !

For Even $n_{s}:$ the $(m-n)$ values exhibit typical $1: 2: 4: 5: 8: 10 \times(1: 2: 4)$ pattern.

For Odd $n_{s}$ : the pattern based upon product of the Prime Factors of $\left(n^{2}+4\right)$ is observed.

In either case, the integers 3,6 and 9 are conspicuous by their absence from these $(m-n)$ or $(k-n)$ values.

But, what's about integer 7 ? Consider another example with $n=34$, as shown below.

\begin{tabular}{|c|l|l|l|l|l|l|l|l|l|l|l|l|l|l|l|l|}
\hline $\mathrm{n}$ & 34 & 34 & 34 & 34 & 34 & 34 & 34 & 34 & 34 & 34 & 34 & 34 & 34 & 34 & 34 & 34 \\
\hline $\mathrm{m}$ & 35 & 36 & 38 & 39 & 42 & 44 & 54 & 63 & 74 & 92 & 150 & 179 & 266 & 324 & 614 & 1194 \\
\hline $\mathrm{m}-\mathrm{n}$ & 1 & 2 & 4 & 5 & 8 & 10 & 20 & 29 & 40 & 58 & 116 & 145 & 232 & 290 & 580 & 1160 \\
\hline
\end{tabular}

As any $\mathrm{n}^{\text {th }}$ Metallic Mean $\boldsymbol{\delta}_{\mathrm{n}}$ can give the precise values of other Metallic Means $\boldsymbol{\delta}_{\mathrm{m}}$ and $\boldsymbol{\delta}_{\mathrm{k}}$ by the formula:

$\frac{\boldsymbol{\delta}_{\mathrm{m}} \times \boldsymbol{\delta}_{\mathrm{n}}+\mathbf{1}}{\boldsymbol{\delta}_{\mathrm{m}}-\boldsymbol{\delta}_{\mathrm{n}}}=\boldsymbol{\delta}_{\mathbf{k}} ;$ with $\mathbf{k}_{\max }=\mathbf{m}_{\max }=\mathrm{n}^{2}+\mathrm{n}+4 ;$

Hence, $(m-n)_{\max }=\left(\mathbf{n}^{\mathbf{2}}+\mathbf{4}\right)$ which is the all important Radical in the fractional expression of $\mathrm{n}^{\text {th }}$ Metallic Mean $\boldsymbol{\delta}_{\mathrm{n}}$

In above table with $\mathrm{n}=34,(m-n)_{\max }=1160$

Consider the Prime Factorization of this $(m-n)_{\max }: 1160=1 \times 2 \times 2 \times 2 \times 5 \times 29$ 
Note the bottom row $(m-n)$ in above table with $n=34$, the numbers in the $(m-n)$ row exhibit the characteristic pattern based upon these factors $1,2,5$ and 29. Numbers in this $(m-n)$ row are the $1: 2: 4$ : $5: 8: 10 \times(1: 2: 4)$ multiples of the prime factors $1,2,5$ and 29 .

Noticeably, the integer $\mathbf{7}$ is present not directly as (m-n), but it's present only as the Digital Roots of certain (m-n) values; for instance the red shaded number 232 in above example. Such presence of $\mathbf{7}$ as Digital Root of (m-n) values is observed with $n=8,10,11,14,16,22,26,29,34,36,39$, and so on. Remarkably, with $n=26,36,39$, etc. multiple $(m-n)$ values are found to have their digital root Seven.

However, the integers 3, $\mathbf{6}$ and $\mathbf{9}$ are invariably missing from this $(m-n)$ pattern, they are neither present directly as $(m-n)$ value, nor as the digital root of any $(m-n)$ or $(k-n)$ values.

As mentioned above, if $\mathrm{n}$ is multiple of 3 , the Digital Root of $|\mathrm{k}-\mathrm{m}|$ is 3,6 or 9 . And, if $\mathrm{n}$ is NOT multiple of 3 , the Digital Roots of the $|\mathrm{k}-\mathrm{m}|$ value are $1,2,4,5,7,8 \ldots \ldots$. Yes, the $|\mathrm{k}-\mathrm{m}|$ pattern directly includes 7 : for example the Triads like $\boldsymbol{\delta}_{2}, \boldsymbol{\delta}_{3}, \boldsymbol{\delta}_{10}$ where $|\mathrm{k}-\mathrm{m}|$ equals 7 (and also as the Digital Root of $|\mathrm{k}-\mathrm{m}|$ values, in Triads like $\boldsymbol{\delta}_{6}, \boldsymbol{\delta}_{8}, \boldsymbol{\delta}_{60}$ )

The more remarkable aspect of Integer $\mathbf{7}$ in the realm of Metallic Ratios can be observed in the Triads of Metallic Means with $\mathbf{n}=\mathbf{7}$ and Multiples of $\mathbf{7}$.

If $\mathbf{n}=\mathbf{7}, \mathbf{1 4}$, etc. : the values of $\frac{\mathbf{k}}{\mathbf{n}}$ and $\frac{\mathbf{k}+\mathbf{m}}{\mathbf{n}}$ exhibit a very characteristic pattern.

For instance, consider the Triad $\left[\boldsymbol{\delta}_{7}, \boldsymbol{\delta}_{8}, \boldsymbol{\delta}_{60}\right]$

$\frac{\mathbf{k}}{\mathbf{n}}=\frac{\mathbf{6 0}}{\mathbf{7}}=8.571428571428571428571428571428 \ldots \ldots$

$\frac{\mathbf{k}+\mathbf{m}}{\mathbf{n}}=\frac{\mathbf{6 0}+\mathbf{8}}{\mathbf{7}}=9.71428571428571428571428571428 \ldots \ldots$

Note the Digits in Decimal Places : Numbers 3,6 and 9 are conspicuous by their absence from the Repeating Pattern of $\mathbf{5 7 1 4 2 8}$.

Exactly similar pattern is observed in all Triads with $\mathbf{n}=\mathbf{1 4}$ :

like $\left[\boldsymbol{\delta}_{14}, \boldsymbol{\delta}_{15}, \boldsymbol{\delta}_{214}\right]$; [ $\left.\boldsymbol{\delta}_{14}, \boldsymbol{\delta}_{16}, \boldsymbol{\delta}_{114}\right]$; [ $\left.\boldsymbol{\delta}_{14}, \boldsymbol{\delta}_{18}, \boldsymbol{\delta}_{64}\right]$; [ $\left.\boldsymbol{\delta}_{14}, \boldsymbol{\delta}_{19}, \boldsymbol{\delta}_{54}\right]$; [ $\left.\boldsymbol{\delta}_{14,} \boldsymbol{\delta}_{24,} \boldsymbol{\delta}_{34}\right]$; etc. Consider the Triad $\left[\boldsymbol{\delta}_{14}, \boldsymbol{\delta}_{16}, \boldsymbol{\delta}_{114}\right]$

$\frac{\mathbf{1 1 4}}{\mathbf{1 4}}=8.1428571428571428571428571428571428 \ldots \ldots \ldots$

$\frac{\mathbf{1 1 4}+\mathbf{1 6}}{\mathbf{1 4}}=9.28571428571428571428571428571428 \ldots \ldots$ 
And, exactly same are patterns in the Triads with $\mathbf{n}=\mathbf{2 8}, \mathbf{3 5}, \mathbf{5 6}$, etc. among other multiples of Seven; but NOT with $\mathbf{n}=\mathbf{2 1}, \mathbf{4 2}$, etc. where Digital Root of $\mathbf{n}$ is multiple of Three.

Moreover, consider the Triads of Metallic Ratios with $\mathbf{n}=\mathbf{3}$ or $\mathbf{6}$ :

For instance the Triad $\left[\boldsymbol{\delta}_{3}, \boldsymbol{\delta}_{4}, \boldsymbol{\delta}_{16}\right]$ with $\mathbf{n}=\mathbf{3}$

$\frac{\mathbf{k}}{\mathbf{n}}=\frac{\mathbf{1 6}}{\mathbf{3}}=5.3333333333333333333333333333333 \ldots \ldots \ldots$

$\frac{\mathbf{k}+\mathbf{m}}{\mathbf{n}}=\frac{\mathbf{1 6}+\mathbf{4}}{\mathbf{3}}=6.666666666666666666666666666666 \ldots \ldots$

Note the $\mathbf{3 s}$ and $\mathbf{6 s}$ in the Decimal places.

Similarly, the Triads with $\mathbf{n}=\mathbf{6}$, like $\left[\boldsymbol{\delta}_{6}, \boldsymbol{\delta}_{11}, \boldsymbol{\delta}_{14}\right] ;\left[\boldsymbol{\delta}_{6}, \boldsymbol{\delta}_{10}, \boldsymbol{\delta}_{16}\right]$; $\left[\boldsymbol{\delta}_{6}, \boldsymbol{\delta}_{8}, \boldsymbol{\delta}_{26}\right] ;\left[\boldsymbol{\delta}_{6}, \boldsymbol{\delta}_{7}, \boldsymbol{\delta}_{46}\right]$; etc.

$\frac{\mathbf{k}}{\mathbf{n}}=\frac{\mathbf{1 4}}{\mathbf{6}}=2.3333333333333333333333333333333 \ldots \ldots$
$\frac{\mathbf{k}+\mathbf{m}}{\mathbf{n}}=\frac{\mathbf{1 4 + 1 1}}{\mathbf{6}}=4.166666666666666666666666666666 \ldots \ldots$

Further, the Triads of Metallic Ratios with $\mathbf{n}=\mathbf{9}$ and the multiples of nine $\mathbf{9}$ exhibit their own characteristic patterns.

The point is that the Numbers $\mathbf{3}, \mathbf{6}$ and $\mathbf{9}$ exhibit their very peculiar and distinctive attributes, in the dominion of Metallic Numbers.

Moreover, the idiosyncrasy of 3, 6 and 9 is exhibited in several other such patterns of Metallic Means and their Triads.

For instance, if $n$ is multiple of $3:$ the digital roots of $[(m-n)+(k-n)]$ are invariably $4,5,4,5 \ldots \ldots$.

And, if $\mathrm{n}$ is NOT multiple of 3 : the digital roots of $[(m-n)+(k-n)]$ are invariably $\mathbf{3}, \mathbf{6}$, or $\mathbf{9}$, as shown below. 
For example,

consider $\mathrm{n}=30$ (digital root of $\mathrm{n}$ is 3 )

\begin{tabular}{|c|c|c|c|c|c|c|c|c|}
\hline $\mathbf{n}$ & 30 & 30 & 30 & 30 & 30 & 30 & 30 & 30 \\
\hline $\mathbf{m}$ & 31 & 32 & 34 & 38 & 143 & 256 & 482 & 934 \\
\hline $\mathbf{k}$ & 934 & 482 & 256 & 143 & 38 & 34 & 32 & 31 \\
\hline $\mathbf{m}-\mathbf{n}$ & 1 & 2 & 4 & 8 & 113 & 226 & 452 & 904 \\
\hline $\mathbf{k}-\mathbf{n}$ & 904 & 452 & 226 & 113 & 8 & 4 & 2 & 1 \\
\hline Digital Root of (m-n) + (k-n) & $\mathbf{5}$ & $\mathbf{4}$ & $\mathbf{5}$ & $\mathbf{4}$ & $\mathbf{4}$ & $\mathbf{5}$ & $\mathbf{4}$ & $\mathbf{5}$ \\
\hline
\end{tabular}

Likewise, consider $n=29$ (digital root of $n$ is other than 3,6 or 9 )

\begin{tabular}{|c|c|c|c|c|c|c|}
\hline $\mathbf{n}$ & 29 & 29 & 29 & 29 & 29 & 29 \\
\hline $\mathbf{m}$ & 30 & 34 & 42 & 94 & 198 & 874 \\
\hline $\mathbf{k}$ & 874 & 198 & 94 & 42 & 34 & 30 \\
\hline $\mathbf{m}-\mathbf{n}$ & 1 & 5 & 13 & 65 & 169 & 845 \\
\hline $\mathbf{k}-\mathbf{n}$ & 845 & 169 & 65 & 13 & 5 & 1 \\
\hline Digital Root of (m-n)+(k-n) & $\mathbf{9}$ & $\mathbf{3}$ & $\mathbf{6}$ & $\mathbf{6}$ & $\mathbf{3}$ & $\mathbf{9}$ \\
\hline
\end{tabular}




\section{Triangles, Triads, Triples and 3, 6, 9 : Finally the "Triangular Numbers" in $\left[\delta_{n}, \delta_{m}, \delta_{k}\right]:$}

The abovementioned Triads of Metallic Ratios are also found in the Pascal's Triangle. The renowned Pascal's Triangle, having the binomial coefficients in its rows and the Fibonacci Numbers in its shallow diagonals, also substantiates the Triads of Metallic Means in an idiosyncratic manner. Take $\mathbf{m}$ and $\mathbf{n}$ from the Natural Number Diagonal of Pascal's Triangle, then the Triangular Number Diagonal yields the value of $\mathbf{k}$ for the Triad $\left[\boldsymbol{\delta}_{\mathbf{n}}, \boldsymbol{\delta}_{\mathbf{m}}, \boldsymbol{\delta}_{\mathbf{k}}\right]$, as illustrated below in Figures 10, 11 and 12. The details however are described in the work mentioned in Reference [8].

$$
(m-n)=1
$$

$\mathbf{m} \& \mathbf{n}$ are Consecutive Integers on

Natural Numbers Diagonal.

Then, the Adjecent Integer $X$ from

Triangular Numbers Diagonal gives value of $\mathbf{k}$ :

$$
\begin{aligned}
& \mathrm{n}=\left(\begin{array}{l}
n \\
1
\end{array}\right) ; \quad \mathrm{m}=\left(\begin{array}{c}
n+1 \\
1
\end{array}\right) \\
& \text { then, } \mathbf{x}=\left(\begin{array}{c}
n+1 \\
2
\end{array}\right) \\
& \text { and } \mathbf{k}=\mathbf{2} \mathbf{x}+\mathbf{4} \text { as shown here }
\end{aligned}
$$

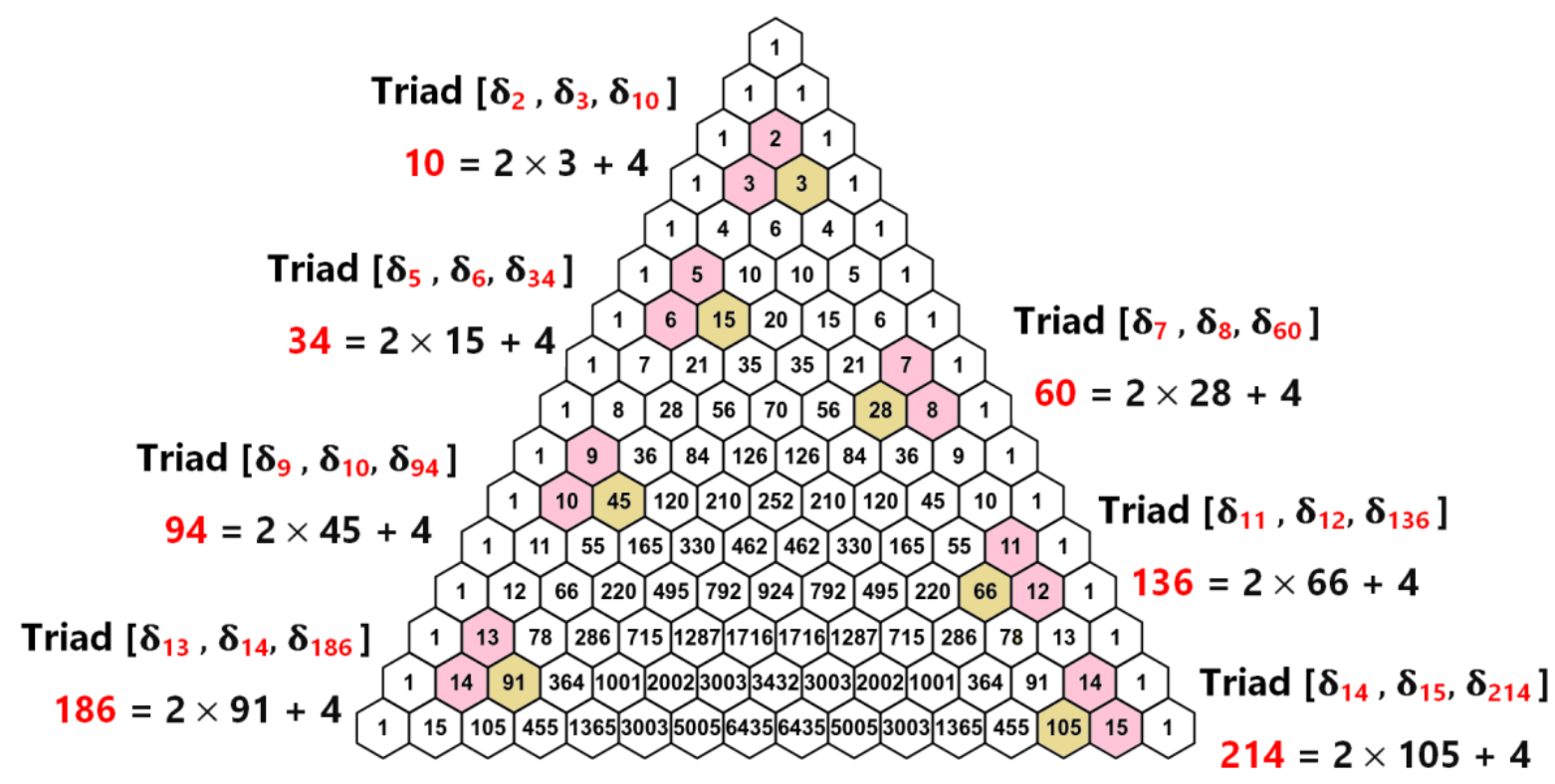

Figure 10: TRIADS of Metallic Means with $\mathbf{m}-\mathbf{n}=\mathbf{1}$, and calculating the value of $\mathbf{k}$ from Pascal's Triangle 
$(\mathbf{m}-\mathbf{n})=\mathbf{2}$ If $\mathbf{n}$ is $\left(\begin{array}{l}n \\ 1\end{array}\right)$ and $\mathbf{m}$ is $\left(\begin{array}{c}n+2 \\ 1\end{array}\right)$; then $\mathbf{x}$ is $\left(\begin{array}{c}n+1 \\ 2\end{array}\right)$ and $\mathbf{y}$ is $\left(\begin{array}{c}n+2 \\ 2\end{array}\right) \quad \mathbf{k}=\frac{(\mathbf{x}+\mathbf{y})+3}{2}$ Triad $\left[\boldsymbol{\delta}_{2}, \boldsymbol{\delta}_{4}, \boldsymbol{\delta}_{6}\right.$
$6=\frac{(3+6)+3}{2}$

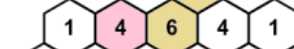

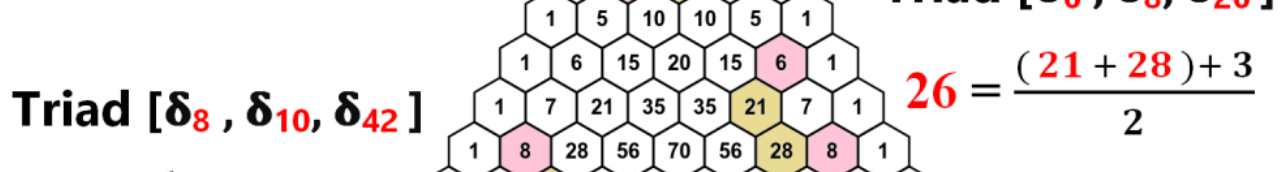

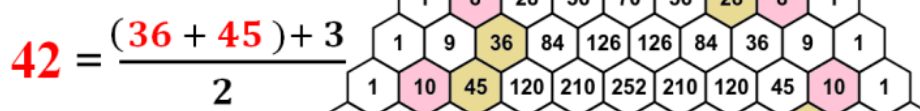

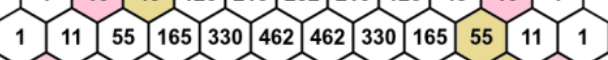

\section{Triad $\left[\boldsymbol{\delta}_{10}, \boldsymbol{\delta}_{12}, \boldsymbol{\delta}_{62}\right]$}

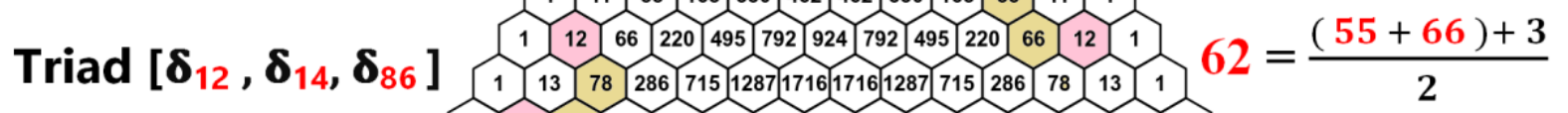

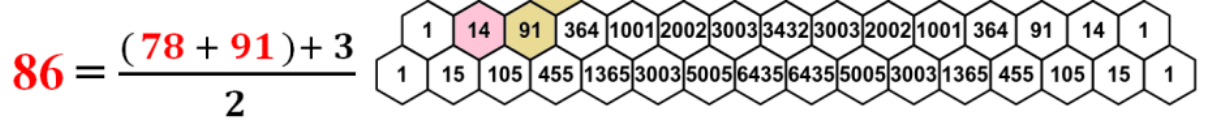

Figure 11: TRIADS of Metallic Means with $\mathbf{m}-\mathbf{n}=\mathbf{2}$, and calculating the value of $\mathbf{k}$ from Pascal's Triangle

$$
\mathbf{n} \text { is }\left(\begin{array}{c}
n \\
1
\end{array}\right) \text { and } \mathbf{m} \text { is }\left(\begin{array}{c}
n+4 \\
1
\end{array}\right) \text {; }
$$

$(m-n)=4$

$\mathbf{W}, \mathbf{x}, \mathbf{y}$ and $\mathbf{Z}$ are the Triangular Numbers from $\left(\begin{array}{c}n+1 \\ 2\end{array}\right)$ to $\left(\begin{array}{c}n+4 \\ 2\end{array}\right)$

$\mathbf{k}=\frac{(w+x+y+z)-2}{8}$

i.e. all Triangular Numbers between $\mathbf{n}$ and $\mathbf{m}$

$$
\begin{gathered}
\text { Triad }\left[\boldsymbol{\delta}_{2}, \boldsymbol{\delta}_{6}, \boldsymbol{\delta}_{4}\right] \\
4=\frac{(3+6+10+15)-2}{8}
\end{gathered}
$$
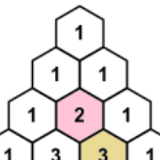

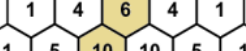

16 (15 201561

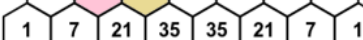

Triad $\left[\boldsymbol{\delta}_{8}, \boldsymbol{\delta}_{12}, \boldsymbol{\delta}_{25}\right]$

Triad $\left[\boldsymbol{\delta}_{10}, \boldsymbol{\delta}_{14}, \boldsymbol{\delta}_{36}\right]$

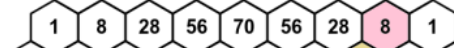

$\begin{array}{lllllllllllll} & 9 & 36 & 84 & 126 & 126 & 84 & 36 & 9 & 1 & 25 & =\end{array}$

$\begin{array}{lllllllllllllll} & 10 & 45 & 120 & 210 & 252 & 210 & 120 & 45 & 10 & 1\end{array}$

$25=\frac{(36+45+55+66)-2}{8}$

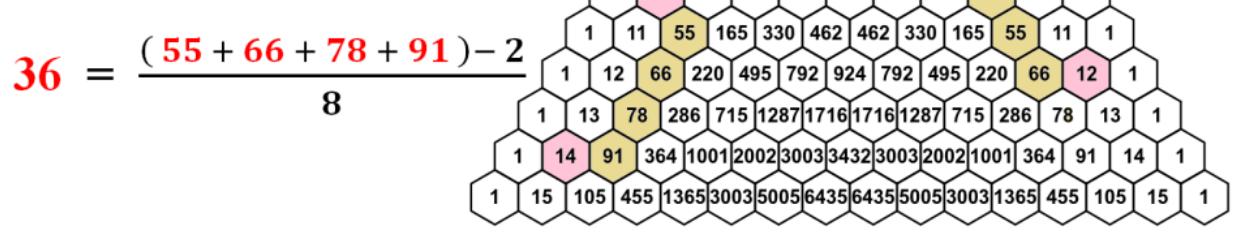

Figure 12: TRIADS of Metallic Means with $\mathbf{m}-\mathbf{n}=\mathbf{4}$, and calculating the value of $\mathbf{k}$ from Pascal's Triangle 


\section{The Mathematical Correlations between various Metallic Means :}

On the last note, it is worth mentioning here that all empirical formulae those provide the precise mathematical relations between different Metallic Means, including the abovementioned intriguing formula $\frac{\boldsymbol{\delta}_{\mathrm{m}} \boldsymbol{\delta}_{\mathrm{n}}+\mathbf{1}}{\boldsymbol{\delta}_{\mathrm{m}}-\boldsymbol{\delta}_{\mathrm{n}}}=\boldsymbol{\delta}_{\mathrm{k}}$; are introduced and elaborated in the work mentioned in Reference [3].

The brief view of those other formulae is as follows:

Different "Odd Powers" of a Metallic Ratio yield the precise values of various Metallic Means by the following formulae;

Consider $\boldsymbol{\delta}_{\mathbf{n}}$ as any $\mathbf{n}^{\text {th }}$ Metallic Ratio.

And let $G_{1}, G_{2}, G_{3} \ldots \ldots . .$. be the Integer Sequence associated with this Metallic Mean $\boldsymbol{\delta}_{\mathbf{n}}$, for example: Fibonacci Sequence for Golden Ratio $\left(\boldsymbol{\delta}_{\mathbf{1}}\right)$, Pell Sequence for Silver Ratio $\left(\boldsymbol{\delta}_{\mathbf{2}}\right)$, and so on.

And, let $L_{1}, L_{2}, L_{3} \ldots \ldots . .$. be the Lucas Sequence associated with this Metallic Mean $\boldsymbol{\delta}_{\mathbf{n}}$, for example: the Lucas Sequence 1, 3, 4, 7, 11...... for Golden Ratio $\left(\boldsymbol{\delta}_{\mathbf{1}}\right)$, and the Pell-Lucas Sequence 2, 6, 14, 34, 82...... for Silver Ratio $\left(\boldsymbol{\delta}_{2}\right)$, and so on.

Let $\mathbf{m}$ be an Odd Positive Integer. The "Odd Powers" of a Metallic Ratio $\boldsymbol{\delta}_{\mathbf{n}}$ can give the precise values of various Metallic Means by the following three formulae;

Formula 1: $\quad \arctan \left(\boldsymbol{\delta}_{\mathrm{n}}\right)^{\mathrm{m}}+\arctan \left(\boldsymbol{\delta}_{\mathrm{n}}\right)^{\mathrm{m}+2}=2 \times \arctan \left(\boldsymbol{\delta}_{\mathbf{k}}\right) ; \quad$ where $\mathbf{k}=\mathbf{2} \times \mathbf{G}_{(\mathbf{m}+\mathbf{1})}$

Formula 2: $\quad \arctan (\boldsymbol{\varphi})^{\mathrm{m}}+\arctan (\boldsymbol{\varphi})^{\mathrm{m}+6}=2 \times \arctan \left(\boldsymbol{\delta}_{\mathbf{k}}\right) ;$ where $\mathbf{k}=\mathbf{F}_{(\mathbf{m}+\mathbf{3})}$

Formula 3: $\quad \arctan \left(\boldsymbol{\delta}_{\mathbf{n}}\right)^{m}+\arctan \left(\boldsymbol{\delta}_{\mathbf{n}}\right)^{3 \mathrm{~m}}=2 \times \arctan \left(\boldsymbol{\delta}_{\mathbf{k}}\right) ;$ where $\mathbf{k}=\mathbf{2} \times \mathbf{L}(\mathbf{m})$

Formulae $\mathbf{1}$ and $\mathbf{3}$ are applicable for all Metallic Ratios, while Formula $\mathbf{2}$ is applicable only in case of Golden Ratio $\left(\boldsymbol{\delta}_{1}\right.$ or $\left.\boldsymbol{\varphi}\right)$.

All these formulae are elaborated with appropriate examples in the work mentioned in Reference [3].

\section{Conclusion:}

This paper introduced and elaborated the purest expressions of various Metallic Ratios in Primitive Pythagorean Triples. Each Metallic Mean, except for the Second Mean, is shown to be epitomized by one particular Primitive Pythagorean Triple. This was the Prime Objective of this paper.

Also, various Right Angled Triangles are shown to represent the Metallic Ratios more holistically than the traditionally considered $\left(n^{2}+4\right)$ gons. This paper elaborated the concept of such special Right Angled Triangles those precisely epitomize the Metallic Means. 
This work also gave a view of the Triads of Metallic Means, their correspondence with Pythagorean Primes, Pascal's Triangle, Numbers 3, 6, 9, etc.

\section{References:}

[1] Rajput, Chetansing (2021). "A Right Angled Triangle for each Metallic Mean". Journal of Advances in Mathematics. 20: 32-33. https://en.wikipedia.org/wiki/Metallic mean\#cite note-15

[2] Rajput, Chetansing (2021). Golden Ratio. JOURNAL OF ADVANCES IN MATHEMATICS, 20, $19-42$. https://doi.org/10.24297/jam.v20i.8945

[3] Rajput, Chetansing (2021). Metallic Ratios : Beyond the Golden Ratio; The Mathematical Relationships between different Metallic Means. JOURNAL OF ADVANCES IN MATHEMATICS, 20, 158-166. https://doi.org/10.24297/jam.v20i.9023

[4] Rajput, Chetansing (2021). "Metallic Means : Beyond the Golden Ratio, New Mathematics and Geometry of all Metallic Ratios based upon Right Triangles, The Formation of the Triples of Metallic Means, And their Classical Correspondence with Pythagorean Triples and $p \equiv 1(\bmod 4)$ Primes, Also the Correlation between Metallic Numbers and the Digits 36 9", JOURNAL OF ADVANCES IN MATHEMATICS, 20, 250-266. https://doi.org/10.24297/jam.v20i.9056

[5] Rajput, Chetansing (2021). Metallic Means and Right Triangles: The Geometric Substantiation of all Metallic Ratios JOURNAL OF ADVANCES IN MATHEMATICS, 20, 167-173. https://doi.org/10.24297/jam.v20i.9029

[6] Rajput, Chetansing (2021). Golden Ratio and other Metallic Means: The Geometric Substantiation of all Metallic Ratios with Right Triangles. JOURNAL OF ADVANCES IN MATHEMATICS, 20, 174-187. https://doi.org/10.24297/jam.v20i.9034

[7] Rajput, Chetansing (2021). Metallic Ratio Triads, The Mathematical and Geometric Relations between different Metallic Means, Metallic Numbers and the Right Angled Triangles. JOURNAL OF ADVANCES IN MATHEMATICS, 20, 167-173. https://doi.org/10.24297/jam.v20i.9077

[8] Rajput, Chetansing (2021). Metallic Ratios and Pascal's Triangle : Triads of Metallic Means in the Pascal's Triangle.

JOURNAL OF ADVANCES IN MATHEMATICS, 20, 167-173. https://doi.org/10.24297/jam.v20i.9078

[9] Rajput, Chetansing (2021). Metallic Ratios and the Digits 36 9,_Mathematical Relations between different Metallic Means,_And the Special Significance of Digits 3, 6, 9 in the realm of Metallic Numbers. JOURNAL OF ADVANCES IN MATHEMATICS, 20, 167-173. https://doi.org/10.24297/jam.v20i.9076

[10] Rajput, Chetansing (2021). Metallic Ratios, Pythagorean Triples \& $p \equiv 1(\bmod 4)$ Primes : Metallic Means, Right Triangles and the Pythagoras Theorem. JOURNAL OF ADVANCES IN MATHEMATICS, 20, 167-173.

https://doi.org/10.24297/jam.v20i.9075 


\section{About The Author:}

Dr. Chetansing Rajput is an M.B.B.S. Doctor from Nair Hospital (Mumbai University, India) and currently working as Asst. Commissioner (Dept. of State GST, Govt of Maharashtra, India). Being a doctor-turnedbureaucrat, author has not received any formal education in Mathematics, does not have even any of the basic

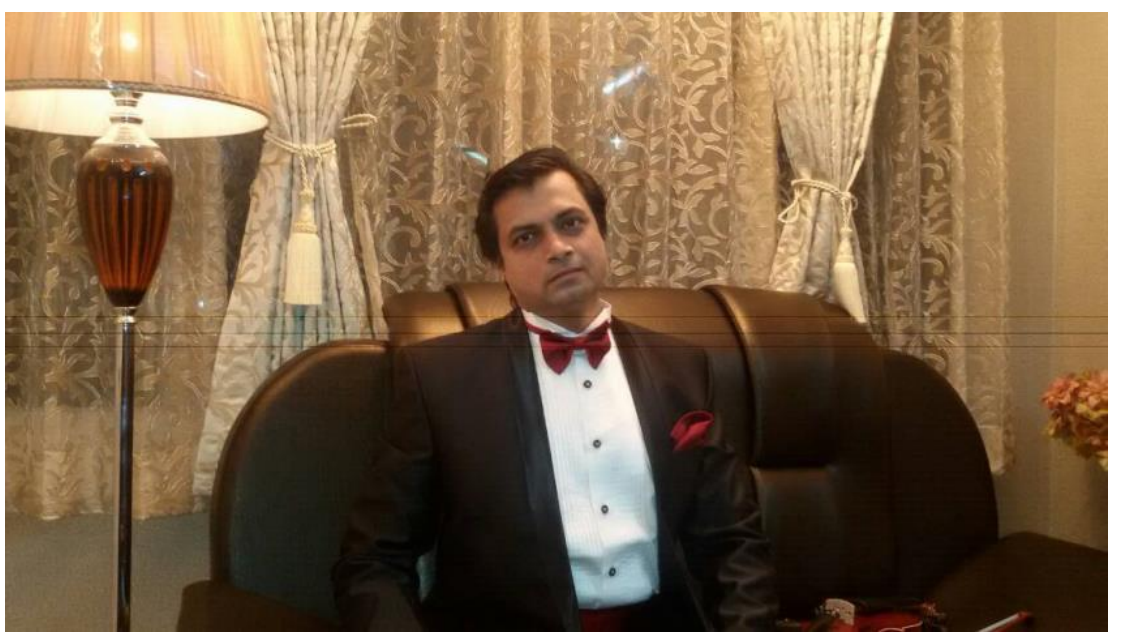
degrees in Maths. All the findings communicated in author's various publications are the results of his home based, self sponsored research pursuits, in the name of Science and Mathematics. Author has also put his sincere efforts, for the inclusion of Golden Ratio and Metallic Means in schools, colleges and university curriculums, through induction programmes, lectures series and seminars, beside popularising these concepts through his publications and the Website: https://goldenratiorajput.com/

\begin{tabular}{|ll|l|}
\hline Select Lecture Videos of Author: & Contacts: \\
1) & https://youtu.be/LFW1saNOp20 & Website: https://goldenratiorajput.com/ \\
2) & https://youtu.be/vBfVDaFnA2k & Email: chetansingkrajput@gmail.com \\
3) & https://youtu.be/raosniXwRhw & Email: chetansingkrajput1129@gmail.com \\
4) & https://youtu.be/74uF4sBqYjs & Contacts: (+91) 7057521129 \\
5) & https://youtu.be/Qh2B1tMl8Bk & \\
\hline
\end{tabular}

